AN EVALUATION OF A PRISON EDUCATION

PROGRAM

BY

LINDA A. PERRY

\begin{abstract}
A THESIS
SUBMITTED TO THE FACULTY OF GRADUATE STUDIES

IN PARTIAL FULFILMENT OF THE REQUIREMENTS FOR THE DEGREE

OF MASTER OF ARTS
\end{abstract}

DEPARTMENT OF SOCIALOGY

WINNIPEG, MANITOBA

October, 1982 


\section{AN EVALUATION OF A PRISON EDUCATION \\ PROGRAM}

BY

LINDA A. PERRY

A thesis submitted to the Faculty of Graduate Studies of the University of Manitoba in partial fulfillment of the requirements of the degree of

MASTER OF ARTS

(C) 1982

Permission has been granted to the LIBRARY OF THE UNIVER-

SITY OF MANITOBA to lend or sell copies of this thesis, to the NATIONAL LIBRARY OF CANADA to microfilm this thesis and to lend or sell copies of the film, and UNIVERSITY MICROFILMS to publish an abstract of this thesis.

The author reserves other publication rights, and neither the thesis nor extensive extracts from it may be printed or otherwise reproduced without the author's written permission. 


\section{TABLE OE CONTENTS}

Acknowledgements

i.

Abstract

ii.

Page

1. Prison Education I

Introduction I

Review of the Literature $\quad 2$

$\begin{array}{ll}\text { Summary } & 21\end{array}$

2. Description of the Project 23

Selection of Inmates 24

Design of the Study 25

$\begin{array}{ll}\text { Educational Program } & 27\end{array}$

Comparison of Experimental and Control Groups 28

Comparison of Volunteers with Inmates in the General Prison Proulation 34

Edication Impact of the Program 38

Methodological Considerations 41

3. Impact of the Program on Prisonization 44

Measurement of the Variables 49

Results $\quad 53$

Discussion of the Findings 63 
4. Impact of the Educational Program on the Inmates' Social Bonãs

Control Theory

Periinent Literature

68

Measurement of the Variables

73

Results

78

Discussion of the Findings

89

5. Impact of the Program on Recidivism 91

Measurement of the Variables 93

Results 96

Discussion of the Findings 112

6. Conclusion 115

$\begin{array}{ll}\text { Bibliography } & 166\end{array}$ 
1. Number of University Courses Completed by the Inmates

2. Number of Inmates by Type of Response to the Question: "What do You Think the 'Donner' Program has Done for You?"

3. Responses to the Item: "Project Inmates Will be Less Likely to Violate Parole."

4. Analysis of Variance for conformity to Staff Norms

5. Conformity to Staff Norms

6. Responses to the Item: "I Would Talk About Personal Matters:"

7. Responses to the Item: "I Would Let Myself be Punished by Institutional Officials for Something I Didn't Do:"

8. Responses to the Item: "I Would Share My Food and Cigarettes:"

9. Responses to the Item: "When I'm Released I Would be Willing to Invite Into MY Home: "

10. Responses to the Item: "Which of These Tells Best How You Relate to Other Inmates:"

11. Responses to the Item: "One Shouldn't Have Too Many Inmate Friends Fiere, Because Inmate Friends May Get You Into Trouble of Take Advantage of You."

12. Responses to the Item: "You Can't Stand It In Here Unless You Have Friends To Talk To." 
14. Analysis of Variance For Criminal Association Preference

15. Responses to the Item: "A Person Like Myself Hasn't Much To Lose By Committing A Criminal Offence."

16. Responses to the Item: "Money Is The Only Reason To Have A Job."

17. Responses to the Item: "A Person Should Never Stop Trying To Get Ahead."

18. Responses to the Item: "What Do You Think Are Your Chances of Being Returned To Prison At Some Time In The Future?"

19. Responses to the Item: "Do You Think That Members of Your Family will Do What They Can To Help You When You Get Out?"

20. Responses to the Item: "Do You Think That Relationships with Your Family will Be Better After Your Release Than Before You Came To Prison?"

21. Responses to the Item: "Do You Think That Your old Friends Will Want To Go Around With You After You Get Out?"

22a. B.C. Penitentiary Inmates: Help Expected From Deviant Versus Conventional Friends After Release

22b. Matsqui Inmates: Help Expected From Deviant Versus Conventional Friends After Release 
Page

3. Responses to the Item: "Do You Think That Relationship with People You Work For Will Be Better After Your Release Than Before You Came To Prison?"

24. Responses to the Item: "Nothing In Life Is Worth The Sacrifice of Losing Contact With My Family."

25. Responses to the Item: "My Family Has Confidence In Me."

26. Analysis of valiance for orientation to Criminal Means

27. Post-Release Success of Project Inmates

28. Gammas for Recidivism and Possible Intervening Variables

39. Drug Use by Post-Release Success

30. Alcohol Use by Post-Release Success

31. Drug Use by Post-Release Success Controlling for Alcoholism

32. Alcohol Use by Post-Release Success Controlling for Drug Addiction

33. Period of Employment After Release by Post-Release Success

34. Perception of the Importance of Correctional Goals by Group

35. Perception of the Importance of Correctional Goals by Post-Release Success

36. Problems Encountered by Inmates on Release from Prison by Post-Release Success

37. Long Term Plans by Post-Release Success 


\section{Acknowledgements}

I would like to thank my advisor, Professor Rick Linden, for the tremendous amount of time and effort he contributed to this thesis and for his continued support throughout my graduate school experience. I would also like to thank Professors Boldt, Anderson and Breen for their invaluable assistance and encouragement.

I am grateful to my husband, Roger Greig, for his understanding and support in this undertaking.

Finally, I would like to express my appreciation to Janice Greig for the time and effort she expended typing the final draft of this thesis. 


\section{Abstract}

During the 1970's researchers began to question the notion that criminals could be rehabilitated in prisons. The findings of evaluation studies tended to show that rehabilitation programs had no effect on recidivism. These studies, however, were few in number and were generally poorly done. This thesis presents an evaluation of a university level eaucational program carried out in British Columbia Penitentiary and in Matsqui Penitentiary between April and August of 1972. The design of the study was a pre-test, post-test experimental design. Inmate volunteers were randornly assigned to experimental and control groups. The program involved full-time attendance in a program which offered remedial instruction followed by university courses in English and History. In addition, inmates were allowed to take additional self-instructional courses in Sociology and Psychology. The program was evaluated in terms of the effects it had on prisonization, inmates' social bonds and recidivism rates. The findings do not indicate that the program affected inmates' level of prisonization, however, the quality of the indicators used to test the hypothesis is questionable. Inmates' social bonds to conventional society may have been increased as a result of their participation in the program, however, the findings are ambiguous and few of them were 
statistically significant. The findings also suggest that inmates who participated in the education program had lower recidivism rates than inmates in the control groups. While the differences are small, they are encouraging. In conclusion, the findings of this study support the contention that there is need for more well-designed and carried out evaluations of prison education programs. 


\section{Chapter 1 \\ Prison Education}

Introduction

There is an on-going debate among those who work in the area of corrections concerning the effectiveness of rehabilitation programs. During the 1970 's researchers began to question whether inmates could be rehabilitated. This questioning stemmed from the growing number of evaluations which showed that rehabilitation programs had no effect on recidivism. More recently the wisdom of this shift has been questioned. Researchers point out that evaluations of prison education programs have been rather infrequent and generally have been poorly done. As well, they note that more current studies have shown some positive effects. This suggests that there is a definite need for more research in this area. The purpose of this thesis is to evaluate a prison education program which was carried out simultaneously at British Columbia Penitentiary and Matsqui Penitentiary between April and August of 1972. The study utilizes a pre-test, posttest experimental design as well as follow-up interviews. The program will be evaluated in terms of the impact it had on prisonization, inmates' social bonds and recidivism. 
Review of the Literature

Educational programs have existed in prisons for many years. In the early 1800 's such programs consisted of instruction in religious matters by visiting or resident chaplains. Secular education programs in reading and writing were later included to enable the inmates to read the Bible and other religious Iiterature (Sutherland and Cressey, 1978:578). Education was believed to be rehabilitative insofar as it enabled the inmate to become more spiritually enlightened.

It was not until the 1870's that education was given a major role in the rehabilitative process. Zebulon Brockway, the superintendent of Elmira Reformatory established mandatory education programs in order to "discipline the mind and fit it to receive....the thoughts and principles that constitute their possessors good citizens" (March, 1973:140). Elmira was not, however, a typical institution and it was not until the 1930's that such programs became a standard offering in most prisons. It was well into the 20 th century before education became divorced from ethics (Weir, 1973). Royal Commissions in 1914 and 1936 both recommended that work programs give way, to some extent at least, to more humanitarian rehabilitative programs including academic and vocational education (Weir, 1973). While some changes occurred following both of these commissions, it was not until 1946 that education began to play a major role in institutional programming. By the 
1970's, "inmate training" was established as the main kind of program for inmates.

While basic academic and vocational education programs have been common in prisons for a number of years, post-secondary programs are a relatively recent development. As late as 1960 college level programs in the U.S. were available for imates in only 9 states (Laird, 1971).

The expansion of prison education and other rehabilitative methods was viewed with optimism in the 1950's and 60's. The promise of the rehabilitative ideal - "that criminal offenders can be reformed or their behavior changed in such a way that they can live socially productive lives in the larger commity without engaging in more criminal activity than most of their fellow citizens" - strongly influenced decisions made by judges, penologists, and policy makers (Sechrest et al., 1979:11).

In contrast to this optimism the $70^{\prime} \mathrm{s}$ could be characterized as the "nothing works" decade. A number of evaluations of research done on the effectiveness of treatment in the field of corrections supported this argument (Martinson, 1974; Bailey, 1966; Robinson and Smith, 1971; and Lipton et al., 1975).

Martinson's (1974) study is perhaps the most commonly cited by these people who declare the concept of rehabilitation defunct. Studying data on the results of 231 programs conducted between 1945 and 1967, Martinson (1974:25) writes: "With few and isolated exceptions, the rehabilitative efforts that have been reported so far have had no appreciable effect on recidivism." 
Martinson's study has not gone unchallenged (cf. Palmer, 1975; Adams, 1976; Halleck and Witte, 1977; Serrill, 1975). Palmer criticized Martinson for going beyond his own findings. He contends that Martinson only considered programs effective if they could work for everyone. The result of this was that treatment methods which had been of value to only some offenders were classified as unsuccessful. Palmer states that 48 percent of the studies reviewed by Martinson had positive or partly positive results. Halleck and Witte point out that most correctional rehabilitation programs are so limited in duration and quality that the failure to achieve dramatic alterations in personalities is not surprising. They also note that Martinson reviewed such a variety of programs that some variants that yield negative results should be expected. Serill's criticism of Martinson's study concerns the amount and quality of research evaluated. Martinson examined research on programs conducted before 1967, however, Serrill states it was only after 1967 that the prison reform movement got into full swing. Furthermore, he adds, research was one of corrections' most deficient areas prior to 1967. As evidence for this Serrill cites the fact that of the more than 1200 studies Martinson found in the literature, only 231 included data that was "interpretable." Inspite of these challenges, the dissolution of the rehabilitative ideal has led to a major shift in orientation away from rehabilitative programs and toward policies emphasizing deterrence, punishment and incapacitation (Wilson, 1975). Curiously, however, the last twenty or so years has witnessed a rapid expansion of programs and facilities relating to prison education. Reagen and Stoughton, who have researched the 
development of prison education quite extensively have suggested that the new emphasis on education is one of the most significant developments in contempory penology: "Prisons emerged two hundred years ago as industrial centers, with opportunity for penitence. They are gradually transforming themselves into educational institutions, by processes and under influences that are not fully understood" (1976:92). While there has been a rapid expansion of educational programs, there have been few attempts to evaluate their success. Further, most of the studies which have been carried out have suffered from methodological flaws which have made it difficult to interpret their results. One of the earliest evaluations looked at the effects of attendance at the fulltime day school of Wisconsin State Prison on recidivism rates. In this study, Schnur (1948) compared the recidivism of 680 prison students with 1082 controls over a two-year period following release from prison. While the experimental and control groups were unmatched, an attempt was made to standardize the two groups on the basis of factors associated with both recidivism and participation in the school program. After standardization, the two groups were compared and it was found that there were relatively small but statistically significant differences between them. One additional finding of relevance to policy-makers was that no effects were observed until the men had attended school for six months or more. While the results of this study were indeed promising, it must be remembered that the statistical adjustment used could not control for factors such as the motivation of immates, which may have differentiated between the school attenders and non-attenders. 
Another early study was carried out by Saden (1962) at the Michigan State Prison. Critically examining the prison files of 1000 men paroled between 1945 and 1949, Saden found that former prison students were more successful on parole than non-students. Unfortunately no attempt was made, either by sampling or statistical manipulation, to ensure the comparability of the school or non-school groups. Similarly, the findings of the study carried out at the Marion (Ohio) Correctional Institution indicated that parolees who had participated in academic or vocational training programs did significantly better on parole than did members of the non-school group (Cochran, 1965). Again the lack of pre-treatment comparability of the school and non-school groups weakens the strength of the conclusions that can be drawn based on these findings.

Contrary to the positive relationship between education and crime reduction reported in the studies above, Glaser's (1969) findings indicate that inmates enrolled in academic education in prison and higher failure rates than those who were not enrolled. However, Glaser does not conclude that prison education programs are harmful, but instead he attributes these findings to several other factors. The first is the academic background of the inmates who officials put into the prison educational program. It seems that officials choose inmates who have little academic training but who are of normal intelligence. These inmates are poor risks for post-release success because they have low prospects for economic self-sufficiency at legitimate employment on the outside. The second factor involves the competition education sometimes has with other activities. It may be that some inmates would have 
benefited more from other activities. Thirdly, inmates who enroll in the educational program may do so only to impress the parole board and not because they sincerely desire to improve themselves. Lastly, education may raise an inmate's vocational aspirations upon release. In support of this, Glaser's findings indicate that post-release success was higher than average only for inmates who had extensive education in prison during a fairly lengthy confinement.

Lipton et al. (1975) have summarized several studies of prison education. They conclude from their detailed assessment of these studies that such programs are successful in their task of training and educating both adult and youthful offenders, but they are not successful in rehabilitating them. However, a review of the studies this conclusion is based on reveals that the impact of such programs on institutional adjustment, post-release employment record and recidivism is mixed.

Three studies which were summarized by Lipton et al. (1975) were concerned with the effects of educational and vocational programs on institutional adjustment. Two of these studies, reported by Jacobson and McGee (1965) found that boys involved in an intensive educational program had a significantly larger number of institutional offences than boys who had been involved in the routine care of the institution. A third study by Zivan (1966) found that institutional adjustment 
for boys who had received 10 months of services from an integrated and phased vocational rehabilitation program was no different than it was for the control group who received standard institutional care. Contradictory results are obvious in studies which looked at the impact of prison training on subsequent occupational adjustment. Sullivan and Mandell (1967) report that inmates who participated in a program which combined academic education with special training in the use of IBM equipment had better post-release employment success than did a group of controls who did not have this training. Contrary to these positive findings, Gearheart et al. (1967) reported that inmates who had vocational training had less success staying on a job after release from prison than those who did not have the training. Several of these studies discussed above have also been concerned with the impact of education on recidivism rates. Of these, the only clearly positive report in this area came from the Sullivan and Mandell (1967) study. They report that after one year the recidivism rate for the experimentals was $48.0 \%$ as compared with $66.0 \%$ for controls. One other program which also was found to have a positive impact on recidivism was the New Start project in Denver, Colarado (Kovacs, 1967). After one year a smaller proportion of the experimental boys, who under went a "non-institutional multiple-impact educational program", including vocational training, role-playing, 
Lorton, Virginia. The program included job-oriented basic remedial education in addition to vocational training. Upon release, job placement, counselling and follow-up services were provided to the graduates. While Leiberg does not present any data on the length of time the inmates included in the follow-up have spent in the community. $74.0 \%$ of the released trainees were considered to have been "successes" in that they had not been re-institutionalized. Unfortunately, this study suffers from the lack of a control or comparison group. Although this limits the inferences one can draw from this study, one important implication which is suggested in the results is that extensive post-release support in the first months immediately following release may enhance an inmates attempts to adjust successfully.

Yahraes (1973) reported on a program which was carried out at the Draper Correctional Center at Montgomery, Alabama. The program consisted of vocational and academic subjects which were supplemented by a reading laboratory and a seminar program. Yahraes reports that a follow-up of the graduates from the program from one to three years after they had been released shows that $32.0 \%$ had been returned to the institution as compared with the recidivism rate for the state as a whole which was estimated at between 50.0 and $70.0 \%$. He also adds that of these $32.0 \%$, almost half had been returned for technical violations of parole. However, as in 
group counselling, theater and art gallery trips, college class attendance, and some programmed instruction in academic education, were in jail as compared with the controls. Zink (1970) conducted an evaluation of a prison education program at the New Castle Correctional Institution at Wilmington, Delaware. The method of investigation was to examine institution and F.B.I. files of inmates. An experimental group composed of 100 inmates was selected from the files of inmates who had attended school for at least two months while in the prison between 1950 and 1958 and who had since been released. This group was matched with a group of equal size selected from the files of inmates who had not attended school during the trial period. Two two groups were compared on variables relating to personal and criminal history and no statistically significant differences were found. A follow-up was carried out using the F.B.I. follow-up report. The post-release conduct of the experimental and control groups was compared during equated periods three, four and five years after release. The findings of the follow-up indicate that attendance at prison school positively affected the inmates' ability to succeed in society after release. This finding was statistically significant at the .01 level of confidence.

A study by Leiberg (1973) evaluated the effects of a program of vocational training for youthful offenders at 
Leiberg study the absence of a control or comparison group severely reduces the credibility of any statements concerning the impact of the program.

Chalfont (1972) was involved with a prison college program at the Lorton Institution in Virgina. Although the project was not initially set up as a controlled experiment, a matched control group was formed of prison college applicants who failed to enter the program because of early parole, change of plans, or other reasons. Only inmates who had completed high school and who had a maximum of two years remaining until either completion of sentences or eligibility for parole were asked to volunteer for the program. A selection committee then reviewed each application and selected those who were thought to be most suitable. The experimental group consisted of 73 inmates while the post hoc matched control group consisted of 32 .

The program consisted of instruction in Sociology, Mathematics and English at the first-year university level. Inmates who completed the equivalent of first-year university were permitted to attend second-year classes at Federal College in Washington, D.C. Extensive support services were provided to help inmates adjust to the academic and social pressures of college routine. In addition, post-release financial support and employment assistance was provided for some released inmates. 
Evaluating the success of the program in terms of the absence of arrests, Chalfont's findings indicate that $58.0 \%$ of the experimental group and $56.0 \%$ of the control group could be classified as successes. However, when those inmates who were arrested but had their cases dismissed were redesignated as successes, $70.0 \%$ of the experimentals were successful, as compared with $59.0 \%$ of the control subjects. Reker and Meissner (1977) evaluated the effects a Life Skills Program had on an inmate's self-concept, personal orientation, attitudes towards life and life areas, and personality. Although this study was not concerned with the relationship of Life Skills training to recidivism, the findings have important implications for prison education programs. Specifically, it was found that inmates trained in interpersonal communication skills, problem solving abilities and personal management skills have a significantly greater positive feeling of selfworth, a more positive attitude towards life and undergo positive changes in their personalities than inmates who participated in an inmate-initiated creative development program or in the regular prison program. Reker and Meissner suggest that the data support further examination with Life skills training in the re-socialization of inmates.

Jenkins et al. (1973) reported on a program at the Draper Correctional Center in Alabama in which inmates 
received training and basic education. The research design involved a comparison of the post-release behavior of men who had participated in the program and a group of non-participants who were similar to the experimental group in terms of demographic and criminalistic variables. A series of followup interviews were carried out at intervals 3, 6, 12, 18 and 24 months. Information concerning recidivism, social and interpersonal behavior, employment status, income and financial management, housing and public acceptance were collected at each interview. As well, law enforcement records were checked at regular intervals for 3 years after the initiation of the project.

The findings of this study indicate that participation in the program did have a small impact on post-release behavior in the area of employment. The experimental group spent more time working and made more money than did the control group during the first 18 months after release. Jenkins et al. note, however, that attrition was considerably high during the follow-up (30.0\% for the experimentals and $27.0 \%$ for the controls) and variability was great, placing a cautious constraint on these positive findings. The data concerning recidivism show a slight trend for the experimentals to comit fewer major crimes during the first 18 months, however, by the end of 26 months the two groups had virtually identical rates for both major and minor crimes. 
Curry (1974) carried out a study of inmates enrolled in community college programs in North Carolina's correctional institutions. The purpose of the study was to analyze selected academic factors associated with prisoner education and to determine the motivational characteristics of inmates enrolled in these programs. Subjects who were attending 15 community college institutions were asked to volunteer to participate in the study. The data were collected by administering a questionnaire to all subjects.

The findings of the study may indicate that participation in an educational program prepares the inmate for his return to society. Almost $10.0 \%$ of the respondents indicated that taking courses helped to prepare them for their eventual release frorn prison. Another major advantage in taking courses was perceived to be the strengthening of the inmate's conception of himself as a person.' Curry states that inmates are motivated to enroll in courses because of a high degree of intellectual curiosity, as well as a desire to gain insight into themselves as persons. Another significant finding was that $64.0 \%$ of the respondents had positive plans about the future. Obtaining a job (18.0\%) and continuing education pursuits (19.0\%) upon release from prison were the most commonly cited goals.

While the findings of this study are encouraging, it must be recognized that there was no control or comparison 
group employed in this study. Because of this we cannot definitely say that the findings were the result of the educational program. In addition, Curry's failure to investigate the postrelease behavior of the respondents greatly undermines his claim that "prisoner education provides the inmate with psychological preparation for his return to the free society, as well as providing him with marketable skills for his employment" (1974:87). Lacking data pertaining to post-release behavior unfortunately reduces Curry's conclusion to little more than speculation.

Cohen and Filipczak (1971) evaluated a prison education program which was carried out at the National Training School for Boys. The project was designed as a twenty-four hour a day program in which students were assigned to an educational program involving both programmed and regular learning situations. The boys were reinforced for their efforts in the course work through a system of points. These points could be exchanged for a wide variety of goods and services within the institution. While no control or comparison group was employed, those involved in the program did seem to have real and significant increases in educational achievement and measured I.Q. A follow-up was carried out comparing the recidivism of boys released from the program with a "similar group" of boys who had remained in the general population of the institution. These data indicate that while initially 
the project boys had lower recidivism rates, by the third year after release these rates had increased to reach the norm.

Lewis et al. (1973) conducted the evaluation of an experimental educational program based on the humanities at the State Correctional Institution at Camp Hill, Pennsylvania. Inmates selected to participate in the humanities program had somewhat better academic skills than the average inmate. Two matched control groups were employed for comparison purposes. One group was selected from the regular academic program (GED) and the other from the vocational training program. A battery of psychological measures were administered to all three groups at the beginning and end of the humanities program. As well, a 33 month follow-up was carried out and information concerning new criminal offences, work experiences and major problems encountered was gathered. The data of the pre- to post-test analysis indicate that there were more statistically significant changes found among the humanities students, however, not all of these changes were in a "positive" direction. The most important change, according to Lewis et al., was that the humanities students became somewhat more aware of themselves and the realities of their environment. The findings of the follow-up did not indicate any significant differences among the groups on reciaivism rates, employment records or major 
problems encountered after leaving prison. It is important to remember when reviewing the results of this study that all three groups took part in some educational program while in prison.

Lewis et al. conclude that the humanities program, like other rehabilitative techniques, was largely unsuccessful because the overall effect of the prison environment is a barrier to rehabilitation. Their findings indicate that while prison is a negative experience for all inmates, the recidivists found the prison experiences especially negative. Perhaps, they suggest, educational programs can benefit inmates by serving to enrich their lives while they are in prison.

Project Newgate was one of the largest educational programs ever carried out in a prison setting. Seashore and her collaborators (1976) evaluated Newgate programs in five American institutions: the Federal Youth Center in Ashland, Kentucky; the Minnesota state Reformatory in St. Cloud, Minnesota; the New Mexico State Prison in Sante Fe, New Mexico; the Oregon State Prison in Salem, Oregon; and the Rockview State Correctional Institution in Bellefonte, Pennsylvania. These were compared with non-Newgate programs at the Federal Correctional Institution at Lompac, California; the Illinois State Penitentiary - Menard Branch; and the Texas Department of Corrections, Eastham Unit. Besides the program 
evaluations, an inmate follow-up evaluation was carried out in each institution which offered the Newgate program. A random sample of program participants were compared with a control group and a comparison group which were both drawn from inmates released from the same institution. The control. groups consisted of inmates who were academically qualified for the program but who did not participate in it, while the comparison groups consisted of inmates of the general population who were matched with Newgate participants on a number of dimensions including age, I.Q., prior education, and time served.

To measure the effectiveness of the program, Newgate researchers developed a composite measure consisting of recidivism, success in achieving a stable life-style, and the degree to which life goals were realized. It was felt that such an index was a better indicator of program effectiveness than recidivism alone, the most commonly used indicator, because rehabilitation involves a series of gradual steps away from criminalistic behavior. Ignoring other important elements of post-prison adjustment makes it difficult if not impossible for these gradual changes to be revealed. Using this composite index, seashore et al. conclude that participation in a program does not affect postprison behavior. However, it seems that this index may be masking some of the effects of the programs because when each 
of the components of the index is looked at separately, the results are a bit more positive. The first component, recidivism, is equally distributed among all of the groups with the exception of the Pennsylvania group who had a higher success rate than any other group. This is an important finding because this program emphasized transitional and postrelease services more than any of the other Newgate programs.

The second component of the effectiveness index was achieving a stable lifestyle. The principle factors which went into this were employment and/or school attendance, drug and/or alcohol problems, and self-reported criminality. Employment status was one area in which the Newgate program was clearly successful, with an overall difference of about 20.0\% between Newgate participants and control and comparison groups. In regard to drug and alcohol problems, the Newgate groups, particularly in Pennsylvania and Texas, were also more successful than comparison and control groups. Although there were no consistent differences with regard to self-reported criminal involvement, once again the Pennsylvania Newgate participants had far lower rates than any other group.

A breakdown of the third component, realization of life goals, also indicates some masked effects. Although these differences were small, Newgate participants showed somewhat higher job aspirations and a somewhat higher level of occupational achievement than comparison and control groups. 
Unfortunately, the ivewgate project, like most other evaluation programs, suffered from the lack of randomlyassigned control groups. This weakens the claims that can be made about a program since differences may be explained by such factors as higher motivation levels on the part of those who volunteered to take part in the program. This source of possible bias must be considered in any assessment of the implications of this evaluation.

Ayers et al. (1980) carried out an evaluation of a university education program at Matsqui and Kent Institutions in British Columbia. The program offers university level courses mainly in the humanities and the social sciences. The experimental group consisted of inmates who had completed at least two courses and two terms of course work. A matched control group was selected from a list of inmates who had not participated in the education program. Matching was in terms of the type of release and the closest possible day of release. Both groups originally consisted of 65 inmates, however, only 40 of the 65 subjects in the experimertal group could be contacted for interviewing. Those 25 inmates who could not be contacted were compared with those who had been interviewed in order to control for a non-response bias. The two groups were quite similar in terms of basic demographic data.

The experimental and matched groups were compared 
in terms of basic demographic data, criminal activities, criminal history in the family, and "Base Expectancy Score". There were no differences between the groups on age, length of sentence, prior criminal activities and on Base Expectancy Scores. The major differences were educational attainment prior to incarceration and drug use. While the experimental group had a significantly higher pre-incarceration grade level than the matched group, it also contained significantly more drug addicts. The researchers suggest that the advantage a higher educational attainment gives the experimental group is outweighed by the disadvantages of having more drug addicts.

The findings of the follow-up indicate that participants of the University of Victoria Program suffered less failure than the control group. The study also provided evidence that attitude change, cognitive devlopment, improved employment opportunities and changed life goals all play a role in facilitating avoidance of trouble with the law. Ayers et al. conclude that the effects of the program on students are significant and long term.

\section{$\underline{\text { Summary }}$}

Evaluations of prison education programs have been rather infrequent and in general have been poorly done. The Iiterature reveals that the impact of such programs is 
little more than speculation when we turn to measures of success such as post-release employment and recidivism. The evidence is ambiguous and it is safe to say that no consistent positive effects have been observed for either of these measures of post-release adjustment.

While positive effects are not obvious in evaluation studies, the poor quality of these studies and the education studies being evaluated must be taken into consideration. Recent work such as Project Newgate and the University of Victoria program has provided some cause for optimism and has suggested some important principles for improving the quality of education programs offered in prisons. It is not unrealistic to speculate that improving the quality of education programs offered and refining the techniques used to evaluate their success will lead to more positive results. 
Description of the Project

The Donner Project was carried out in two Federal prisons in the Iower Mainland of British Columbia. These were the British Columbia Penitentiary, a maximm-security, custody-oriented institution, and Matsqui Penitentiary, a medium-security prison. The program took place between April and August of 1972 .

The aim of the program was to provide a university-level educational program for inmates of the two institutions. Researchers who carried out the program attempted to achieve the following goals:

1. To make the inmate participant more self-confident and better able to express himself. The educational qualifications received should make the inmate more employable and the skills taught should make it easier for him to hold a job.

2. To bring about certain attitude and personality changes which would prepare students to cope more successfully with society and its institutions.

3. To develop awareness and, hopefully, incorporate more mature values using traditional English and history courses as vehicles for such development.

4. To provide students with the basis for further education, either cultural, vocational, technological or academic. The basis for continuing education includes the development of the necessary work and study habits and confidence to pursue further education. 
Selection of Inmates

Selection of inmates for the program was done on a volunteer basis. In order to facilitate the follow-up research, admission was restricted to those who might potentially be paroled or released within one year of completion of the program. Additional screening was carried out to ensure that the inmates would be able to cope with the educational program. This involved restricting admission to inmates who had completed at least Grade VIII. Inmates who participated in the study also had to agree to forego transfer to reduced security for the duration of the program.

Volunteers were randomly assigned to experimental and control groups in each institution. In B.C. Penitentiary, 18 inmates were assigned to each group while in Matsqui there were 15 in each group. At B.C. Penitentiary a second "experimental group" was formed at the request of the acministration. This group consists of inmates who expressed an interest in participating in the program, but who were ineligible because of the length of their sentences. Many of these inmates had life sentences and were not expected to be released for many years after the conclusion of the program. This group will not be included in the analysis of data. Inmates in the experimental group were assigned to the school program on a full-time basis, while those in the control groups carried out their normal prison activities.

Volunteering was an important dimension of the program because it precluded those inmates who were not willing to exert 
thenselves . This was important because to undertake a university course requires considerable time and effort, and demands high performance. Inmates who may take the courses only in hopes of making time go by faster, and are not really interested in getting much more out of the program could subvert the whole process of correctional education. Volunteering should also reduce the chances of having a high drop-out rate which could seriously bias the findings. A significant reduction in the number of cases would undermine the reliability of these findings. An important consideration concerning the use of volunteers is the potential bias they may create in the data. Since volunteers were randomly assigned to experimental and control groups, those inmates who were assigned to the control groups may have felt very disappointed at not being able to participate in the program. This may have been reflected in their responses to the items in the post-test and followup interviews. However, the benefits of using volunteers will likely outweigh the potential bias they create in the data.

\section{Design of the Study}

The basic design of the project was a pre-test, post-test experimental design. Prior to the beginning of the educational program, inmates in both control and experimental groups took part in an extensive pre-test session. Following the pre-test the educational program began in the form of intensive academic instruction at the first-year university level. At the completion of the educational program a post-test was carried out which was identical to the pre-test. Unfortunately some of the inmates 
who took the pre-test were not available for the post-test. This creates methodological problems when one tries to compare the pre-test and posttest results. To overcome this problem only those inmates who participated in both the pre-test and post-test were included in the analysis of these data. It was found however that the attrition rate in the Matsqui control group was high enough to warrant the exclusion of this group from most of the analysis. This was caused by refusals from these inmates to participate in the post-test as well as transfers to other institutions. There were only 6 inmates who participated in the testing at both time intervals. This groug will only be included in those parts of the analysis which do not involve comparisons over time.

A follow-up was carried out to measure longer-term effects. It was planned to interview former students as well as members on the control groups about two years after release. This would have been within three years of the end of the program as it was expected that all subjects would be released within one year. However, during the instructional phase a new and tougher parole policy was introduced which resulted in considerable delay in the release of many of the students. Because of difficulties in tracking down many of the inmates the followup was very difficult. However, 47 of the 66 inmates were interviewed. Interview information was supplemented with follow-up data obtained from police and parole records on most of the remaining 19 inmates. Because the inmates were released at different times over a period of about three years, and because of the difficulty in locating some inmates for follow-up interviews, the time interval between the release date and 
the subsequent follow-up interview varies among the inmates.

Both experimental and control group inmates were also interviewed several times during the program, as were several members of the prison staff. These interviews were carried out for evaluation purposes as well as for the purpose of making adjustments in the program while it was in progress. Biographical information was also collected from the inmates' prison files in both prisons. Every fourth file was selected and biographical information about each inmate was recorded. The purpose of this was to determine how representative the inmates in the educational program were of the general inmate population by comparing characteristics of both groups.

Educational Program

The basic educational program consisted of instruction in English and History at the first-year university level. These courses were taught by formal lecture and discussion method for about three hours a day by a qualified teacher. One teacher was assigned on a fulltime basis to each institution and was in the classroom with the students all day. In addition, extensive homework assignments were given to the students so that they were kept busy for up to twelve hours each day. This was done in order to ensure the inmates' total involvement in the project, with the expectation that the high demand characteristics of the program would have a positive effect on levels of achievement. In addition to the courses in English and History, those inmates who were making satisfactory progress were allowed to take additional first-year 
courses in Sociology and Psychology, which were given by selfinstructional packages supplemented by visiting lecturers.

Since the academic backgrounds of the students varied greatly, and some had little preparation for university, remedial instruction was provided for irmates on an individual basis, with an emphasis being placed on reading and language skills. The Raygor series of self-instructional materials was used as the basis for this remedial instruction.

Comparison of Experimental and Control Groups

Prison files and an extensive pre-test questionnaire were examined in order to determine if the randomized experimental and control groups were initially similar to one another. Analysis of variance was used to determine whether or not significant differences existed between the groups. Because of rather extensive differences in the level of security, type of custodial care, and variety of alternate programs available, it was decided to treat the Matsqui and B.C. Penitentiary groups separately.

The data available provided basic demographic information as well as measures of previous criminal activities and institutional adjustment. For both institutions, control and experimental groups did not vary significantly on age, religion, number of children, marital status, or previous occupation and work history. While the work related variables did not differ significantly, there was a pattern of differences which, while small, is worth noting. Members of both control groups were 
slightly more likely to have had skilled or semi-skilled white collar jobs than were members of the experimental groups who were more likely to have been employed as laborers or in semi-skilled blue collar jobs. As would be expected, experimental group members were more likely to have had sporadic work histories and shorter periods of employment. The measured I.Q. levels of all four groups were almost identical (an average of 106), however, there were some significant differences in the level of educational attainment. The Matsqui experimentals had an average of grade 10, which was significantly higher than the average grade level of 8.9 for the controls. The situation was reversed in B.C. Penitentiary where the experimental group had an average level of 9.3 while the average level of the control group was 10 . This difference was not statistically significant.

Iooking at variables related to previous criminal activities, the groups were similar in sentence length, age at first arrest, number of previous incarcerations, number of fines, number of suspended sentences, number of jail terms, number of penitentiary terms, number of escapes, and number of parole violations. The groups did not differ in their perceived propensity for violence or in their adjustment to the institution. However, major differences existed in drug addiction and in drinking problems. While no differences were found in these items in B.C. Penitentiary, in Matsqui it was found that the experimental group had a higher rate of addiction to drugs while the control group was more likely to be involved with excessive alcohol use. Of the 14 members of the experimental group for whom information on drug use was 
available, 11 were addicts and 2 were heavy users of soft drugs. This meant that 93 percent of the experimental group had a drug problem, compared with 55 percent of the controls and about 55 percent of the B.C. Penitentiary inmates who volunteered for the program. On the other hand, the Matsqui controls were significantly more likely to have had an alcohol problem than were the experimentals. Again, there were no differences between the B.C. Penitentiary groups.

Not surprisingly, the higher rate of drug use among the Matsqui experimental group was reflected in the type of offence for which each inmate was currently incarcerated. Of the Matsqui experimental group, 64.3 percent were currently imprisoned on drug-related offences, compared with 42.8 percent of the controls.

A detailed discussion of the items from the pre-test questionnaire is not possible due to the length of this instrument which contains about 270 separate items. Further, with this large number of questions and using the .05 level of significance, we would expect 13.5 items to be significantly different due to chance. For these reasons, in this discussion of the equivalence of experimental and control groups we will look only at differences which appear to be a part of a systematic pattern of differences and which might be expected to have some effect on the results of the project.

There were very few statistically significant differences between the B.C. Penitentiary groups. In all, only 15 items were different at the .05 level. As noted above, this number could be expected to occur by chance. The response means were very close for almost all 
questions, so that the lack of signifcant differences between groups was not attributable to the difficulty in achieving significance with a small number of respondents, but does reflect a real similarity between the groups.

Examination of the questions for which significant differences did exist between the experimental and control groups did reveal one pattern of responses which might have been relevant to the outoome of the program. The control group inmates consistently reported having less favorable relationships with their families than did the experimental group. The controls were less likely to report that they were receiving a lot of support from their families during their stay in the institution. This was supported by the fact that they reported having less correspondence with friends and relatives and fewer visits than were reported by the experimental group inmates. Only 6.3 percent of the experimental group inmates reported having had no correspondence during the last month, compared with 37.5 percent of the controls. Also, 75 percent of the controls and 37.5 percent of the experimentals reported having had no visitors during the previous month. The controls were less Iikely than the experimentals to report that both their fathers and mothers knew most of their friends while they were growing up. This item was intended to provide a measure of closeness to parents during adolescence, and these responses suggest that the differences in the strength of family ties between the two groups was one that preceded the inmates' present sentences. One possible reason for this is suggested by the fact that 87.5 percent of experimentals reported growing up with their real 
mothers compared with 60 percent of the controls. Further, 75 percent of experimentals and 60 percent of controls reported living with their real fathers while growing up.

The responses discussed here indicate that the B.C. Penitentiary experimental group has stronger family ties than the control group. This may have an impact on their post-release adjustment, since support and encouragement from relatives may help an ex-offender become reintegrated into conventional society.

The control and experimental groups in Matsqui were also quite similar. Significant differences were found for only 19 items. As was the case with the B.C. Penitentiary groups, most of these differences did not suggest any basic dissimilarities between groups. The one pattern of differences which did appear relates to the degree of involvement of inmates in a criminal lifestyle. The experimental inmates were less likely than the controls to agree with the statements, "A man should always obey the laws, no matter how much they stand in the way of his ambitions" and, "It is difficult to break the law and keep one's self-respect." Experimentals were more likely to agree with the statement that, "Stealing can be exciting" though less likely to feel that, "It is fun to con people into doing what you want them to do". Responses to questions concerning the nature of their involvement in criminal activities also suggest that the experimentals may have been more committed to their criminality than were the controls. The experimentals were more likely to have reported committing offences numerous times before being caught, and were more likely to have cormitted offences with 
friends who had previously been in trouble with the law. Their higher degree of attachment to deviant friends is also suggested by the fact that the experimentals were more likely to express agreement with the statements, "After I'm released, I'Il probably get into trouble because of my friends" and, "Most of my friends on the outside always seem to be getting into trouble with the police". Further evidence of the degree of involvement of the experimentals in criminal behavior was found in the file data which showed that experimentals were first arrested at an age which was, on the average, over two years younger than that of the controls. While this difference was not statistically significant, it is an indicator of more extensive involvement in criminality.

These data are consistent with the higher incidence of drug addiction among the experimentals. Addicts tend to live a lifestyle which is defined to a great extent by their deviance. They spend a good deal of time in the company of other addicts and identify with a drug subculture. Since the possession and sale of narcotics is illegal, they are involved in repeated violations of the law. Further, many are involved in theft and other criminal acts in order to support their druxg use. While this is the only area in which the experimental and control groups appear to differ, it is an important one in terms of this evaluation since the recidivism rate of addicts is very high, and is not likely to be affected by any kind of rehabilitation program. 
Comparison of Volunteers with Inmates in the General Prison Population

Data from every fourth prison file in both the B.C. Penitentiary and Matsqui Penitentiary were analyzed to determine if the inmates who volunteered to participate in the program are representative of the general inmate population. It is highly improbable that volunteers will be typical of the general inmate population because it would be unreasonable to assume that all inmates would be willing to expend the considerable time and effort required of the participants in the program. It should be noted, however, that the findings of the study are not intended to be generalizable to the general inmate population. They are intended to apply only to those inmates who have the motivation required for them to benefit from participating in an educational program. It is untenable to suggest that all inmates should be given a university education, however, those inmates who desire to at least attempt a university program should be given the opportunity to do so. The data which were analyzed contained biographical information as well as information conceming the immates' criminal activities. The biographical information included age, marital status, level of education attained, I.Q., and use of drugs and liquor. The data pertaining to the inmates' criminal activities included age of first arrest, length of present sentence, offence presently serving time for and the number of jail and penitentiary terms served.

Looking at the biographical variables, some slight differences between the general inmate population and the volunteers are obvious. 
Both the Matsqui and B.C. Penitentiary groups are slightly younger than the general inmate population. The mean age is 29.6 years for the general inmate population, 28.2 for the B.C. Penitentiary groups, and 27.2 for the Matsqui groups. This difference is statistically different for the Matsqui groups, the average age for these inmates being 2.38 years younger than the average age for inmates in the general inmate population.

The large majority of inmates in both prisons are single (57.3 percent). This is represented in both groups of volunteers, with the proportion of single immates being 38.7 percent in the B.C. Penitentiary and 50 percent in the Matsqui group. While a higher proportion of volunteers in the B.C. Penitentiary group are married (25.8 percent) as compared with the general inmate population ( 17.3 percent), the Matsqui group contains a smaller proportion of married inmates (13.6 percent). Both groups of volunteers have a higher proportion of divorced and separated inmates than the general inmate population. The proportions are 11 percent for the general inmate population, 16.1 percent for the B.C. Penitentiary group, and 21.3 percent for the Matsqui group. While the B.C. Penitentiary group contains a higher proportion of common-law relationships (19.4 percent) as compared with the general inmate population (12.6 percent), the Matsqui group contains a smaller proportion (9.1 percent)

The average level of education attained by volunteers in both prisons is statistically significantly higher than it is for inmates in the general prison population. Inmates in the general prison population 
have an average education attainment level of Grade 9, while the Matsqui and the B.C. Penitentiary volunteers have an average of 9.6 grades. Correspondingly, volunteers at both institutions have statistically significantly higher measured I.Q. levels than inmates in the general prison population. The average I.Q. level for the general inmage population is 104 while it was measured at 106.3 and 107 for Matsqui and B.C. Penitentiary volunteers respectively.

It is apparent that slight biographical differences between inmates who volunteered for the program and inmates in the general prison population exist. When variables pertaining to the use of liquor and drugs are considered, however, highly significant differences are apparent. The proportion of drug addicts and alcoholics among the Matsqui volunteers is significantly higher than it is for the general prison population. The situation is reversed at the B.C. Penitentiary with the proportion of drug addicts and alcoholics among the voluntoers being under-representative of the general inmage population. The proportion of inmates in the general prison population who are anug addicts is 48.5 percent, as compared with 32 percent in the B.C. Penitentiary sample and 65.2 percent in the Matsqui sample. Similarly, the proportion of alcoholics is 29 percent for the general inmate population, 17 percent for the B.C. Penitentiary group, and 44 percent for the Matsqui group. Looking at variables pertaining to criminal activities again reveals slight differences between the inmates in the general prison population and the volunteer groups. Volunteers in both prisons had a mean age of first arrest which was statistically significantly lower as 
compared with the general inmate population. The general inmate population had a mean age of first arrest of 19 years as compared with 18 years for the volumteer groups at both Matsqui and B.C. Penitentiary.

To compare the general prison population and the volunteers in terms of the length of sentence presently being served, some modifications have to be made to the statistics to compensate for the fact that inmates with life sentences were not permitted to enter the education program. The sample of inmates in the general prison population included 16 inmates with life sentences and the average length of sentence for this sample was 17 years. Simply by excluding those inmates with life sentences from the sample the average length of sentence decreases to 4.7 years, as compared with 4 years for the Matsqui volunteers and 3.5 years for the B.C. Penitentiary volunteers. The difference between these means is statistically significant for the Matsqui group only.

The volunteer groups and the general inmate population have some notable differences in terms of the types of offences comitted. Corresponding with the high proportion of drug addicts in the Matsqui group, this group also had a higher proportion of drug related offences than the general inmate population. This was the case for the type of offences they had committed in the past; as well as the offence they were institutionalized for during the time the program was carried out. While the B.C. Penitentiary volunteers are actually fairly representative of the general prison population in terms of the type of offences committed, one slight difference is worth noting. The B.C. Penitentiary volunteers seemed to have committed more offences involving violence than the 
general inmate population. Most commonly this violence was combined with a property or drug offence.

Both the Matsqui and B.C. Penitentiary volunteers are representative of the prison population in terms of the number of jail and penitentiary terms served. The average number of jail terms served was 3.5 for the general inmate population, 3.2 for the Matsqui volunteer group and 3.8 for the B.C. Penitentiary volunteer group. The average number of penitentiary terms was 1.7 for the general inmage population, 2.0 and 1.9 for the Matsqui and B.C. Penitentiary groups respectively. It appears that inmates who volunteered for the education project at both Matsqui and B.C. Penitentiary were fairly representative of the general inmate population. The major differences were related to the disproportionately high number of drug addicts and alcoholics in the Matsqui group. This was related to the type of offences cormitted by volunteers in this group.

Educational Impact of the Program

Before the effects of any program are evaluated, it is important to first determine whether inmates were in fact active and involved participants and not merely passively exposed to it. A number of researchers, among them Gendreau and Ross (1979), have been critical of much of the evaluation research which has been carried out in correctional institutions on the grounds that often the "programs" that are being carried out are programs in name only. Studies often lack any measure of whether inmates actively participated in a program or were 
just exposed to it. For this reason an attempt will be made in this section to determine how well the educational goal of this program was accomplished.

One of the difficulties of implementing a university program in prison is that few inmates have graduated from high school. This is not to suggest that inmates have below normal intelligence. Glaser $(1969 ; 174)$ notes that at worst inmates have measured I.Q.'s which are, on the average, only slightly below that of the general population. Inmages who volunteered to participate in this program did demonstrate this pattern of nomal intelligence and below-average educational achievement. The average measured I.Q. for the B.C. Penitentiary experimental group was 108 and for the Matsqui experimentals was 107. The average number of grades completed, however, was only 9.3 and 10 for the B.C. Penitentiary and Matsqui experimental groups respectively. This was despite the fact that the minimum educational level required of those volunteering for the project was Grade 8 .

Despite the limited background of some of the students, the program was very successful in achieving its educational goals. The majority of inmates completed the two full-year credit courses in Fnglish and History which formed the core of the educational program, and a number of them also completed full-year Introductory-level courses in Sociology and in Psychology. Table I shows the number of courses completed by inmates in the two institutions.

In addition to the high course completion rate, the grades received by students also indicates the success of the program. Of 
those who received final course grades, 59 percent of the B.C. Penitentiary students and 46 percent of Matsqui students received grades of ' $B-$ " or higher. It should also be noted that only one student in Matsqui and two in B.C. Penitentiary withdrew from a course. The first was in English while the latter two were in History.

Following the completion of the program inmates in the experimental groups and a few control group inmates were interviewed. Their responses to the question, "What do you think the 'Donner' Program has done for you?", indicated positive attitudinal and behavioral changes took place. As opposed to focusing on the value of the course to help them make parole and to obtain jobs or get aomitted to university after their release, the major focus of the responses was the effect the course had on their thinking. In fact, their responses indicated something of a revelation that political, moral and social issues usually had at least two sides, that it was possible to take different sides of an issue. An example of the kind of change that took place was that in one of the institutions only two of the experimental group inmates subscribed to a daily paper when the course began compared with thirteen by the end of the course. Other responses to this question, shown in Table 2, centered around the comminication value of the course. These responses dealt with things like feeling more competent in a situation such as a job interview, or when talking to educated people.

In the post-test survey inmates were asked if they felt the project would have an effect on the parole success of participants. The results shown in Table 3 indicated that the majority of experimental 
inmates agreed that school program inmates would do better on parole. In response to an open-ended question which asked inmates to describe the ways in which they were helped during their stay in prison, twothirds of the experimental inmates first mentioned education. Further, experimentals were less likely than controls to respond that their prison stay had not helped them at all.

The program clearly accomplished the goal of providing inmates with university-level training. Despite the poor preparation which most of the inmates had for university courses, nearly all were able to complete the two core courses, and some exceeded this level. The grades received by students compare quite favorably with those achieved by students attending regular university programs. As well, the participants expressed the belief that the program had a positive effect on their way of thinking and helped them to build up their self-confidence. There is no doubt that the experimental inmates were active, involved participants in this highly demanding program.

\section{Methodological Considerations}

While the design of this study provides an ideal situation for evaluating the education program, factors beyond the control of the researchers reduced the number of inmates who participated in both the pre-test and post-test. As a result the Matsqui control group had to be excluded from those parts of the analysis that involved comparing the experimental and control groups over time. The number of inmates in the B.C. Penitentiary control group who could be compared over time was 
also reduced as a result of uncontrollable factors. Only 10 of the 18 inmates in this group who took the pre-test were available to take the post-test.

As a result of having to exclude one control group and having the number of inmates in the other control group so severely decreased, the extent to which the data can be statistically analyzed is very limited. This potential bias in the data should always be taken into consideration when the results of this study are being interpreted and unfortunately the conclusions are often reduced to little more than speculation.

A second consideration for the interpretation of these data involves factors which potentially could have interfered with the overall success of the programs. The researchers who carried out the project judged that overall the B.C. Penitentiary program was more of a success than the Matsqui program. At Matsqui the custodial staff was less co-operative and classes were often interrupted. From the inmates' point of view, there was more competition in Matsqui from other programs and from various recreational and hobby activities. The inmates had less time to devote to studying than did the B.C. Penitentiary inmates who had little to do but to go to class and study. This difference between the two programs may be reflected in the findings and will have to be taken into consideration.

The analysis of the data basically took the form of analysis of variance between the experimental and control group in the pre-test and the post-test. Multiple-item indexes were constructed for some of 
the variables and coefficient alpha was computed for each. The internal consistency of the index was considered to be acceptable if alpha was .60 or greater. A low reliability coefficient can result if the number of items or the number of subjects is small, or if the items have little in common (Nunnally, 1967). This suggests that an index that has a low reliability coefficient is probably not measuring any one specific variable. Because of this, caution should be exercised when the findings are being interpreted. 


\section{Chapter 3}

Impact of the Program on Prisonization

Treatment programs operate within a social context. In this study, the social context is the formal and informal social organization of the prison. The social context may have serious implications for the outcome of the treatment program. Kassebaum et al. (1971:142) state: "...the individual's position in the informal social organization may have implications for his participation in, and reaction to, many aspects of institutional programs, including the treatment program."

The existence of the "inmate social system", also known as the "prisoner community", or the "inmate culture", has been well documented in the literature (eg. Clemmer, 1958: Sykes, 1958; Sykes and Messinger, 1960). This culture is generally derived from two sources: the conduct norms directed to the inmate by the administration, and the conduct norms of the inmate community. The norms from these two sources are mutually exclusive, meaning that the inmate must either behave in accordance with administrative rules or inmate rules (Wellford, 1967). The conduct norms of the inmate community, known as the inmate code, have sanctions to enforce conformity that tend to be more severe than those used by the staff 
(McCleery, 1960). The two most general components of the code are opposition to the prison staff and collective solidarity among inmates.

Kassebaum et al. (1971) explain that adherence to the inmate code creates an internal conflict within the inmate. A novice to the prison quickly learns that adherence to the inmate code will make his life in prison much easier. This is because the inmate code exhibits features of a protective ethos such as advice functional for adjustment and elements of solidarity. At the same time, however, the novice is told to "look out for himself", and the realities of prison life, such as competition for goods, contradict the ideal of solidarity. As a result, many inmates individually are distrustful of other inmates and they express a preference for isolation rather than solidarity with other inmates.

Clemmer (1958) was the first writer to concern himself with the impact prison has on inmates. He introduced the concept of prisonization to describe the process by which inmates assimilate the inmate culture. It was his contention that no inmate could remain completely unprisonized. As well, he felt that certain conditions influenced both the degree and speed of prisonization, the most crucial of these being the extent to which the inmate involved himself in primary group relationships within the prison.

Since 1958 when the concept of prisonization was 
first introduced criminologists have studied this process quite extensively. This research has shown the extent to which various factors are related to prisonization. These factors include organizational characteristics of the prison (Grusky, 1959; Akers et al., 1977), length of time incarcerated (Clemmer, 1958; Wheeler, 1961; Wellford, 1967; Atchley and McCabe, 1968), phase of imprisonment (Wheeler, 1961; Wellford, 1967), degree of alienation (Tittle, 1964; Thomas, 1975, 1977), type of social role adaptation within the inmate social system (Sykes, 1958; Garabedian, 1963; Wellford, 1967; Thomas and Foster, 1972, 1973), the inmate's post-prison expectations (Wheeler, 1961; Glaser, 1969; Thomas and Foster, 1972; Thomas, 1975, 1977), interpersonal relationships with other inmates (Clemmer, 1958; Wheeler, 1961; Atchley and McCabe, 1968) and relationships with others outside of prison (Clemmer, 1958; Thomas and Foster, 1973; Thomas, 1975, 1977).

Prisonization is now a common term to those who are involved with the study of prisons. The effects of this process have been an ongoing concern, especially to those who are attempting to rehabilitate criminals. Being sentenced to imprisonment means that the inmate is faced with rejection from society and deprivation and regimentation at the hands of the prison staff. This will influence him to "regard the staff as an enemy and unite with other inmates, at least in terms of 
a common hate object" (Lewis, 1973:36). Adherence to the inmate code means that the inmate rejects the value orientation of the administration and, thus, fails to internalize and accept as legitimate the goal of rehabilitation. As a result inmates do not voluntarily participate in their own rehabilitation which is felt to be a necessary condition before rehabilitation can take place (Etizioni, 1975). Thomas (1977:58) states:

....high degrees of assimilation into coercive organizational settings rather clearly imply levels of opposition to the formal organization that are counterproductive to the attainment of change goals by the prison and, moreover, the adoption of attitudes and values that increase the likelihood of reinvolvement in criminality upon release from the institution.

Thomas and Foster (1972:230) summarize the three potential consequences of prisonization as follows:

(1) the development of attitudes which reflect opposition both the the formal organization of the prison and to its programs;

(2) the development of attitudes which ascribe a high priority to interpersonal associations with other inmates; and

(3) the development of increased criminal identification.

It is likely that for a treatment program to be successful in reducing recidivism rates, inmates' involvement 
in the inmate social system must be decreased significantly. The research of Jenkins' et al. (1973) substantiates this by showing that prisonization does have consequences for the long-term life-chances of the inmates. By categorizing inmates as non-law violators or law violators and high or low on a scale of prisonization these researchers show that the degree of prisonization is positively related to post-release law-violating behavior. These findings must be interpreted cautiously, however, because variables such as age, prior record, length of sentence, and so on, were not controlled. If initial differences between the recidivists and nonrecidivists are related to the degree of prisonization, then the recidivism rates may be due to prisonization or to their poorer initial prognosis.

Glaser (1969), in his extensive study of federal prisons, concludes that contacts with meaningful others can compete successfully with the influence of the peer group. He argues that an inmate can identify with and assimilate conventional values when he has meaningful relationships with responsible, caring adults who respect conventional values and have succeeded in life through the conventional channels.

Referring to the impact prison has on inmates Gerard (1978:113) states:

If the universities and colleges had some success with prisoners, it may have been because they were not part of the prison 
system. They were regarded as being part of a 'real' society which many were eager to enter and from which many prisoners felt excluaed."

An educational program which enables inmates to have meaningful learning experiences and to establish substantial interpersonal relationships with responsible, caring adults should weaken inmates' endorsement of the inmate code and cause them to become less involved in the inmate social system.

Hypothesis 1: Inmates in the experimental group become less prisonized as a result of participating in the program.

Measurement of the Variables

To measure the degree of prisonization three indicators of the concept were used. They are conformity to staff norms, expressed solidarity among inmates and isolation from others. The first indicator, conformity to staff norms, refers to the extent to which inmates accept pro-social staff goals. Using five hypothetical conflict situations developed by Wheeler (1961) an index of conformity to staff norms was developed. The five items which make up this index are:

\footnotetext{
"An inmate, Owens, is assigned to a work crew. Some other inmates criticize him because he does more work than anyone else on the crew. The other inmates feel that the officer will soon start making them
} 
work as hard as Owens. Owens decides to work as hard as before."

"Inmate Martin does before a committee that makes job assignments. He is given a choice between two jobs. One job would call for hard work, but it would give Martin training that might be useful to him on the outside. The other job would allow Martin to do easier time in the institution, but it provides no training for a job on the outside. Martin decides to take the easier job."

"An inmate, without thinking, commits a minor rule infraction. He is given a "write-up" by a correctional officer who saw the violation. Later, three inmates are talking to each other about it. Two of them criticze the officer. The third inmate, Sykes, defends the officer, saying that he was only doing his duty."

"Inmates Smith and Long are very good friends. Smith has some whiskey that was smuggled into the institution by a visitor. Smith tells Long he thinks the officers are suspicious, and asks Long to hide the whiskey for him for a few days. Long takes the whiskey and carefully hides it."

"Inmates Brown and Henry are planning an escape. They threaten inmate Smith with a beating unless he steals a crowbar for them from the tool shop where he works. He thinks they mean business. While he is trying to smuggle the crowbar back from the tool shop, he is caught by an officer and charged with trying to escape. If Smith doesn't describe the whole situation, he may lose up to a year of good time. He may avoid it by blaming Brown and Henry. Smith decides to keep quiet and not blame Brown and Henry." 
Responses to the items are on a six category approvedisapprove continuum. When combined to make up the index of conformity to staff norms the items have a reliability coefficient of Alpha=.71 in the pre-test and Alpha=.62 in the post-test.

The second indicator of the degree of prisonization is the expressed solidarity of the inmates. This was measured by the following four items:

"I would talk about personal matters:"

To no inmate.

only to my close friends in here. only to inmates I know well. To any inmate.

"I would let myself be punished by institutional officials for something I didn't do:"

Never Only to protect a close friend. To protect inmates that I know well. To protect any inmate at all.

"I would share my food and cigarettes:'

With no one. Only with my close friends. Only with inmates that I know well. With any inmate.

"When I'm released I would be willing to invite into my home:"

No one who has ever done time. only those inmates that are my close friends. Only those inmates that I know well. Any inmate. 
The reliability coefficient for these items is very low $(.40$ in the pre-test and .49 in the post-test). Therefore, these items cannot be said to be measuring the expressed solidarity of the inmates. Each item will be examined separately.

The final indicator of prisonization, isolation from other inmates, is measured by the following three items:

(1) "Which of these telis best how you relate to other inmates:"

Try to stay to myself as much as possible.

Try to know many inmates but not be very friendly with any of them.

Try to make a few inmate friends. Try to make as many friends as I can among the other inmates.

(2) "One shouldn't have too many friends here, because inmate friends may get you in trouble or take advantage of you."

(3) "You can't stand it in here unless you have friends to talk to."

Responses to the last two items were on a seven category agree-disagree continuum. Again these items have a low reliability coefficient (Alpha=.32 in the pre-test and .07 in the post-test). This lack of internal consistency indicates that we do not know what these items are measuring. These findings will be analyzed separately for each item. 
$\underline{\text { Results }}$

The first indicator of prisonization is conformity to staff norms. Analysis of variance was run for each time in the index in order to compare the B.C. Penitentiary experimental and control groups in both the pre-test and post-test. There were no statistically significant differences between the groups on any of the items in the post-test and only one item was significantly difference between the groups in the pre-test. This was the second item or hypothetical situation which asked inmates to indicate whether they thought it was preferable for an inmate to take a job that allowed him to do easier time in prison or one that required hard work but also provided training for a job on the outside. The findings indicate that the control group thought an inmate should choose the easier job while the experimental group thought the harder job that provided training was a better choice. When the items were combined to form the index the analysis of variance between groups did not indicate any statistically significant differences between the experimental and control groups (Table 4).

These data were also analyzed by classifying inmates as high conformists, medium conformists, and low conformists, according to the number of situations in which the inmate's response indicates disapproval of anti-administration code behavior. High conformists disapprove of anti-administration 
code behavior in at least four of the five situations, medium conformists disapprove in two or three situations, while those who disapprove in one or none of the situations are low conformists. Disapproval of anti-administration code behavior is represented by approval of the inmate's conduct in items one and three and disapproval on items two, four and five (Wheeler, 1961).

The findings, reported in Table 5, do not indicate any differences in the inmates' level of conformity to staff norms as a result of having participated in the education program. In both the pre-test and post-test in the B.C. Penitentiary experimental group had a slightly higher level of conformity to staff norms than did the control group. While there was an increase in the level of conformity from the pre-test to the post-test, this occurred in the control group as well as the experimental group, indicating that the education program could not be attributed with causing this change. Similarly, at Matsqui the experimental group had an increase in their level of conformity to staff norms, however, in the absence of a control group no conclusions can be drawn. The second indicator of prisonization is the expressed solidarity of the inmates. Four different items were used to measure this variable. The first item asks inmates who they would discuss personal matters with (Table 6). There were no statistically significant differences 
between the experimental and control groups in either the pre-test or the post-test. At B.C. Penitentiary most inmates in both the experimental and control groups tended to say they would discuss a personal matter with no inmate or only with a close friend within the institution. It is interesting to note that in the pre-test inmates in the experimental group tended to respond by saying they would not talk to any inmates $(46.7 \%)$ but in the post-test $53.3 \%$ said they would talk to their close inmate friends. There was no change at all in the control group. This may indicate that the program encouraged friendship bonds to develop between the participants. The findings at Matsqui were very similar in that they also show a lack of willingness to discuss personal matters with any inmate other than close friends. In contrast to the B.C. Penitentiary experimental group, however, this group expressed more willingness to confide in other inmates in the post-test than in the pre-test.

The second item asked inmates under what circumstances they would let themselves be punished by institutional officials for something they didn't do (Table 7). This item is derived from one of the basic rules of the inmate code: "do not snitch". Informing on other inmates would permanently jeorpardize an inmate's position with other inmates. His actions would never be forgotten by the inmate community and he could expect the victim of his actions to seek revenge and 
chastisement by the inmate community. It is also probable that this form of punishment would be more harsh than the punishment he would receive from institutional officials. Therefore, this item may reflect fear of the consequences of violating the inmate code.

The findings from this item also do not support the hypothesis that participating in the education program decreases the level of prisonization. The greatest porportion of inmates in all groups indicated that they would let themselves be punished by institutional officials for something they didn't do to protect inmates that they knew or to protect any inmate at all. At the B.C. Penitentiary a greater proportion of the control group responded that they would protect most other inmates than did the experimental group in both the pre-test and the post-test. Similar to the previous item, the proportion of inmates who would protect most other inmates increased from the pre-test to the post-test in both the experimental and control groups. In the pre-test $53.3 \%$ of the experimental group and $66.7 \%$ of the control group indicated a willingness to protect other inmates and in the post-test $66.6 \%$ of the experimental group and $77.8 \%$ of the control group responded this way.

The findings at Matsqui are very similar, however, the inmates at this institution did not express as much willingness to be punished by officials to protect other inmates 
as did the B.C. Penitentiary inmates. While the experimental group in this institution also expressed more willingness to protect most other inmates in the pre-test than in the posttest, this difference was very small.

The third item asked inmates who they would share their food and cigarettes with (Table 8). It is highly unlikely that men who already suffer many deprivations would be willing to share the few things they do have with others, however, that is not what this item is intended to measure. It is intended to measure the extent to which inmates "say" they would be willing to share as opposed to the extend to which they actually do share. Unfortunately, a major weakness of this item is that it does not specify the conditions under which sharing would occur. While the findings from this item will be discussed in this thesis, they will be given little significance.

The findings from B.C. Penitentiary indicate that inmates in both the experimental and control group increased their willingness to share with any inmate from the time of the pre-test to the post-test. While the experimental group had a slightly greater increase than the control group, the differences between the groups was not statistically significant. The pre-test findings indicate that $60 \%$ of the experimental group said they would share with inmates they knew well and $33.3 \%$ said they would share with any inmate. In the 
post-test the respective figures are $40 \%$ and $53.3 \%$. In the control group pre-test $30 \%$ said they would share with inmates they knew well and $40 \%$ would share with any inmate. These proportions increased to $40 \%$ and $50 \%$ respectively in the posttest.

The findings from the Matsqui experimental group also indicate a very high willingness on the part of inmates to share their food and cigarettes, however, the difference from the pre-test to the post-test is very small and statistically insignificant. In the pre-test $83.3 \%$ said they would share with inmates they knew well or any inmate at all compared with $91.6 \%$ in the post-test. This item does not give any indication that participation in the program affects inmates' expressed willingness to share with each other.

The last item asked inmates who they would be willing to invite into their home after they are released (Table 9). The findings from this item are more positive in the sense that they do suggest that inmates expressed less willingness to have other inmates in their homes as a result of participating in the program. This was only so for the B.C. Penitentiary experimental group. In the pre-test $42.8 \%$ of the B.C. Penitentiary experimental group compared with $60 \%$ of the control group said they would invite inmates they knew well or any inmate into their home after release. In the post-test $21.4 \%$ of the experimental group and $70 \%$ of the control group responded this way. 
This indicates that the number of inmates in the experimental group who expressed a willingness to have other inmates in their homes was greater in the pre-test than in the post-test, while the number of inmates in the control group who expressed this was greater in the post-test than in the pre-test. This difference between groups in the post-test is statistically significant at the .035 level of confidence. The findings from this item suggest that participation in the program does reduce inmates' inclination to want to invite ex-inmates into their homes.

Contrary to the findings from B.C. Penitentiary, the Matsqui experimental group expressed more willingness to have ex-inmates in their homes in the post-test than in the pretest. In the pre-test $50 \%$ expressed a willingness to invite inmates into their homes compared with $66.7 \%$ in the post-test.

In summary, these findings do not indicate that participation in the program affected inmates' expressed willingness to discuss personal matters with other inmates, to be punished by institutional officials to protect other inmates, or to share with other inmates. They do indicate that the program may have affected the inmates' desire to be with other ex-inmates after they were released. B.C. Penitentiary experimentals were less inclined to express a willingness to invite ex-inmates into their home after they were released than were controls. This difference between the groups was statistically 
significant in the post-test. It is interesting to note that this was the only item which was concerned with inmates' plans for their lifestyle after release. All of the other items were concerned with their way of dealing with other inmates and problems which arise because of their imprisonment. It may be that these other items are measuring what the inmate feels he must do to make his life bearable within the institution, and this is probably independent of his plans for the future. Also, the program required a rather high level of interaction among participants which may be reflected in feelings of wanting to include other program inmates in their personal lives. This will be discussed in more detail later in this chapter.

The last indicator of prisonization is isolation from other inmates. The first item is intended to measure whether an iniuate prefers to have inmate friends or to isolate himself from others while in prison. The findings, reported in Table 10, tend to differ between the two prisons. Inmates in both the B.C. Penitentiary experimental and control groups expressed more of a preference to keep to themselves in the post-test as compared with the pre-test. From the pre-test to the post-test the proportion of inmates in the experimental group who preferred to be alone increased from $26.6 \%$ to $46.6 \%$. In the control group the increase was from $45.5 \%$ to $63.6 \%$ 
The findings from the Matsqui experimental group again are not consistent with those from B.C. Penitentiary. This group tended to become a little more friendshiporiented over time. In the pre-test 33.3\% were friendshiporiented compared with $41.7 \%$ in the post-test. This change is very small and not statistically significant. In general the findings from this item do not suggest that the education program had any effect on inmates' preference for isolation or friendship as a way of relating to other inmates. The second item asked inmates to agree or disagree with the following statement: "One shouldn't have too many friends here, because inmate friends may get you into trouble or take advantage of you." While the differences between the experimental and control group were not statistically significant, there are some findings that are worth mentioning (Table 11). First of all, in the pre-test $13.3 \%$ of the B.C. Penitentiary experimental group expressed that they trusted inmate friends compared with 36.4 of of the control group. In the post-test $46.7 \%$ of the experimental group compared with $27.3 \%$ of the control group responded in this manner. This shows that inmates in the experimental group were opposed to inmate friends in the pre-test but tended to favor them in the post-test. The findings from the control group were similar to this in the sense that there was a relatively large decrease (36.4\% to $9.1 \%$ ) in the proportion of inmates 
who did not think it was a good idea to have too many inmate friends, however, the proportion who felt they should have many friends did not correspondingly increase as it did in the experimental group. In fact the proportion who favored having many frienas actually decreased from $36.4 \%$ to $27.3 \%$. These findings may suggest that participating in the program makes inmates feel more confident that they can have inmate friends who can be trusted.

Contrary to the findings at B.C. Penitentiary the inmates at Matsqui expressed more distrust of inmate friends at the conclusion of the program than they did before it began. In the pre-test $33.4 \%$ of the experimental group agreed with the statement that inmate friends get you in trouble or take advantage of you compared with $58.3 \%$ in the post-test. The final item used to indicate isolation was whether inmates thought they needed friends to talk to while they were in prison. There were statistically significant differences between the B.C. Penitentiary groups in both the pre-test and post-test (Table 12). At both times the experimental group agreed with the item while the control group expressed indifference. In the pre-test $60 \%$ of the experimental group agreed that having friends to talk to was important compared with $18.2 \%$ of the controls. This difference was statistically significant at the .031 level of confidence. This indicates that inmates in both the experimental and 
control groups felt it was more important to have friends to talk to in the pre-test than they did in the post-test.

At Matsqui the findings are in the opposite direction to those from B.C. Penitentiary, but again the difference from the pre-test to the post-test is very small. In the pretest $50 \%$ thought that having friends to talk to while in prison was important, while in the post-test $58.3 \%$ thought this way.

In summary, the findings from these three items concerning how inmates prefer to relate to other inmates are ambiguous. While the program did not seem to have any effect on their preference for isolation or friendship, the ambiguity of these findings makes it difficult to draw any conclusions.

\section{Discussion of the Findings}

The findings concerning the effects participation in the education program has on an inmate's level of prisonization are ambiguous, however, it can be concluded that in general the program did not have any effect on the level of prisonization.

The first indicator, conformity to staff norms, did not vary significantly between the B.C. Penitentiary experimental and control groups in either the pre-test or the posttest. In both of these groups as well as the Matsqui experimental group there was an increase in the level of conformity 
from the pre-test to the post-test. One finding which is worth noting is that the Matsqui inmates tended to conform to staff norms more than the B.C. Penitentiary inmates did. This finding is not unexpected because Matsqui is a medium security institution while the B.C. Penitentiary is a maximum security institution. Inmates at Matsqui have a wide variety of programs to chose from so they have more contact with staff members. As well, these inmates are not subject to the same degree of deprivation as are inmates at the B.C. Penitentiary. These factors may act to reduce hostility toward the staff members at this institution.

The second indicator of prisonization is expressed solidarity. Adherence to the inmate code should theoretically lead an inmate to respond in a manner which indicates that there is an enormous degree of solidarity among inmates. Kassebaum et al. (1971) state that solidarity is considered to be the ideal of the inmate subculture. While we cannot be sure that the indicators are measuring expressed solidarity, the findings of this study do not indicate that the degree to which inmates express cohesion was affected by the program. The third indicator which was used to measure prisonization was the degree of isolation inmates preferred to have from one another. Kassebaum et al. (1971) say that the ideal of solidarity is contradicted by the realities of prison life. 
Inmates learn that they can't trust other inmates and must fend for themselves. The result of this is that inmates have a preference for isolation at the same time they are expressing the ideal of solidarity. The findings of this study concerning isolation are ambiguous and therefore are difficult to draw any conclusions from. Generally they do not indicate that inmates' preference to keep to themselves or to have inmate friends is affected by the program. Most inmates express a preference for a few inmate friends, and they tend to feel that they need friends to talk to while they are in prison. The best that can be concluded is that the findings do not suggest that praticipation in the program affects how inmates relate to each other.

In conclusion, the findings of this study do not support the hypothesis that inmates in the experimental group become less prisonized as a result of participating in the program. The education program's ineffectiveness in weakening inmates' endorsement of the inmate code may be a consequence of the short duration of the program. When you take into consideration that inmates who volunteered for this program had previously served an average of 3.5 jail terms and 2 penitentiary terms and were serving an average sentence term of 3.75 years at the time of this program, it is not surprising that a four-month program did not effect their degree of prisonization. A second possible explanation for these 
results may be the motivation of the inmates who took part in the program. It is not inconceivable that those who volunteered for the program were not motivated to do so by their desire to rehabilitate themselves. It is possible for an inmate to partake in the program and still adhere to the inmate code.

A third explanation concerns the nature of the program itself. Participation in the program required intensive interaction among the inmates and therefore encouraged inmates to develop relationships with each other. Because the inmates who participated in the program were volunteers it is possible that they shared some common interests. These common interests as well as the large anount of time they spent together makes it highly probable that the inmates did develop relationships with each other. The result of this, however, is that the indicators of prisonization may actually be indicators of the quality and intensity of the relationships the inmates have developed with other program participants. If this is the case then we would not expect this hypothesis to be supported but instead the findings should reflect the increasing level of intensity and quality of the relationships that have developed among those inmates who participated in the program. 


\section{Chapter 4}

\section{Impact of the Educational Program}

on the Inmates' Social Bonds

Control Theory

According to control theory the person who deviates is one who is free of ties to society. While everyone is viewed as a potential deviant, control theorists explain that those of us who do not engage in deviant behavior have a "stake in conformity". It is the strength of our ties to the conventional system which will determine whether we will conform or deviate from the social order.

Hirschi's (1969) version of control theory proposes that the bonds we have to society are made up of four elements: attachment to conventional persons that would be strained by deviant acts, conventional pursuits that would be jeopardized by a conviction, the time and opportunity required for criminal activities, and a lack of belief in the moral validity of conventional norms. Hirschi's general argument is that as elements of the bond become weakened, deviancy becomes possible, although not necessary.

Control theory has been criticized for not differentiating between attachments to conventional and deviant peers (Linden and Hackler, 1973; Conger, 1976: Hepburn, 1977; Glaser, 1978, 1979; Little, 1979). Because of this deficiency, control theory is unable to account for the observation that 
bonds to pro-criminal society may be conducive to deviancy. Linäen and Hackler (1973), Conger (1976), Hepburn (1977) and Glaser (1978; 1979) contend that control theory can be linked to the reference group interpretation of differential association theory to explain the effects of attachment to deviant peers. Whereas control theory sees the person who deviates as one who is free of ties to society, differential association theory emphasizes the importance of attachment to persons sharing criminal value patterns. The result of integrating these theories suggests that ties to deviant peers, especially in the absence of conventional ties to peers and adults, will be conducive to deviancy (Linden and Hackler, 1973).

The implications control theory has for prison education programs are very serious because incarceration often destroys any bonds an inmate may have with conventional society and provides him with the opportunity to develop relationships with criminally oriented others. Theoretically this suggests that in order for a treatment program to be effective it must develop or strengthen the bonds inmates have to conventional society and weaken their bonds to procriminal society. Research which has investigated inmates' social bonds will be reviewed in the following section.

\section{Pertinent Literature}

Research indicates that inmates who have strong 
family ties have a lower recidivism rate than those who have strong bonds with criminals. Holt and Miller (1972) note that prisoners tend to differ from the general population in respect to their marital status. Prisoners are more likely to be single or to have disrupted marriages. They state that marital status is one of the basic characteristics which has been found to be an important determinate of social relationships. Marriage structures the inmate's ties with the outside world in a complex network of relations. The findings of this study indicate that inmates who have had regular continuing visits from family members have a significantly lower recidivism rate as compared with those who did not have visitors or had only sporadic visits. OhIin (1954) developed an "index of family interest" and found that 75\% of the inmates classified as maintaining "active family interest" while in prison were successful on parole while only $34 \%$ of those considered to be loners experienced success. Glaser (1964) used Ohlin's classification system and found that the success rate for the "active family interest" group was 710 as compared to the loners success rate which was $50 \%$. Unfortunately none of these studies attempted to control for variables such as age, length of sentence and prior criminal record. As a result we cannot be certain that the findings reported are due to family interest as opposed to initial differences which may have existed between the inmates on other relevant variables. 
A study by wilkins (1964) indicates that healthy, rehabilitative relationships can develop among inmates if the peer group is motivated toward rehabilitation. He found that "good risks" (men who were likely to be rehabilitated in prison) were better risks when concentrated with other good risks, and "bad risks" were worse when concentrated with bad risks. The implication is that by giving rehabilitative oriented inmates the opportunity to have more contact with each other than with non-rehabilitative oriented inmates, a correctional program will provide inmates with encouragement and support to maintain or strengthen their conventional bonds. It may not always be the case that inmates who volunteer to participate in correctional programs are oriented towards rehabilitation. There are a variety of reasons why inmates may wish to participate, the most obvious being to impress the parole board, or to reduce the boredom of "doing time."

Glaser (1969) states that most persons committed to prisons do not have a "stake in conformity". That is, they do not have much to lose in terms of status in the community, among friends and relatives, and in their own eyes, by the disgrace of conviction for a criminal offence, nor do they worry that a criminal record will prevent them from obtaining legitimate employment. Even if they do have bonds to conventional society when they enter the prison, it is generally 
agreed that these bonds will become weak and their bonds with criminally oriented others will be strengthened during their time in prison (cf. Glaser, 1979).

Irwin (1970) states that many inmates leaving prison have strong desires to go straight, however, once they are on the outside they usually run into many problems which prevent them from organizing their lives in the manner they had planned. The first step for many ex-inmates involves coping with the initial shock of re-entering the free world. Often ex-inmates find that they are unable to function normally in the free world. The routine, slow-paced lifestyle they lead in prison leaves ex-inmates ill-prepared to function within this strange and unpredictable setting. Planned, purposeful action becomes extremely difficult and taken-for-granted actions, such as ordering food in a restaurant and paying for it, can cause anxiety.

Once the initial impact of life on the outside has passed, the ex-inmate runs into many more difficulties in his attempt to adjust to his new setting. First he must try to provide for himself the very basic necessities. This generally requires that he obtain employment shortly after his release from prison. Since most ex-inmates are unskilled and uneducated, finding employment is often a very difficult task. As well, his ability to go job-hunting is hampered by a lack of funds with which to obtain clothing and transportation, 
and his inability to schedule his time for appointments. For those who are lucky enough to find a job, chances are high that it is rated low in pay and prestige. These factors often enhance the feelings of frustration ex-inmates have (Liker, 1982).

A second major difficulty ex-inmates encounter in their attempts to adjust to the free world involves starting a social life and beginning to enjoy life again. Irwin (1980) says it is common for ex-inmates to find that they no longer have anything in common with old friends and that they can no longer relate to former friends and family. As a result, they become very lonely and may long for the company of their friends from prison. Often inmates released around the same time "hang around" together and these relationships can encourage an ex-inmate to get reinvolved in criminal activities which may eventually lead to his return to prison. It seems that a strong desire to go straight and to break free of bonds with criminally oriented others can quickly deteriorate when confronted with the difficulties an ex-inmate may have to face when he attempts to re-enter society.

Cressey (1954) points out that because criminality is a social problem, social relationships are of primary importance. Therefore, the criminal must develop new relationships with individuals and society. Glaser contends 
that the greatest rehabilitative effect can be achieved by a combination of the deterrence of confinement and a program to increase their stake in conformity by treatment to correct their personal, educational and work deficiences, and by socially integrating them with anti-criminal persons.

Hypothesis 2: Involvement in an educational program will increase the bonds inmates have with conventional society and decrease their criminal bonds.

Measurement of the Variables

The nature and extent of inmates "bonds with others" will be measured using a variety of indicators including: reference group orientation, measures of inmate's "stake in conformity", expectations as to the quality of relationships with family, friends and employers after release, bonds with family members and orientation to criminal means.

Direct and indirect measures of reference group orientation have been analyzed. The direct measure is the extent to which respondents perceive themselves as similar to "general" criminal others, or "criminal identification" (Stratton, 1967). The items used to measure this are:

"People who have been in trouble with the law have the same sort of ideas about life that I have."

"People who never break the law are a lot different from me." 


\begin{abstract}
"I'm more like those people who can make a living outside the law than I am like those who only break the law occasionally."
\end{abstract}

Responses to these questions were on a seven point agreedisagree continuum. The reliability coefficients (Alpha) for these items are .55 for the pre-test and .32 for the post-test. This suggests that some or all of these items may not be measuring criminal identification. These items, along with two others, were included in an index of criminal identification by Stratton (1967). He obtained a reliability coefficient of .71 for the index. Therefore it is possible that the low reliability coefficients obtained for the index in this study are the result of too few items and that these items could be indicators of criminal identification. Unfortunately there is no way for this to be determined.

The indirect measure of reference group orientation is an index of associational preference. The five items which make up the index assess the degree to which the respondents prefer to associate with law breakers. These items are:

"When I get out I don't want to associate with the kind of people that are always getting into trouble."

"I would rather associate with people who obey the law then with those who don't."

"I don't care to associate with the kind of people that are in prison." 


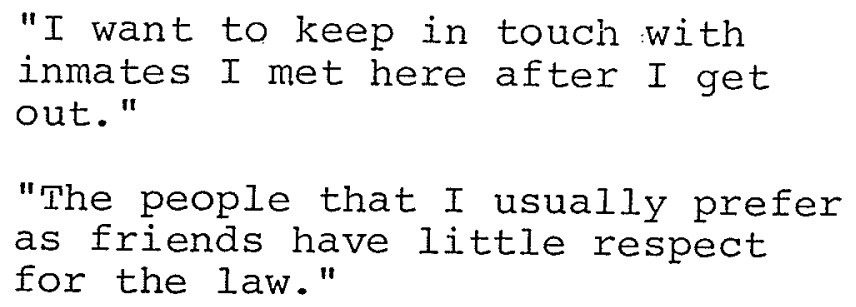

Responses to these questions are also on a seven point agreedisagree continuum. The reliability coefficients of the five items which make up the index are Alpha=.85 for the pre-test and Alpha=.79 for the post-test.

The second indicator of the independent variable "bonds with others" is whether the inmate has a "stake in conformity." Items which measure this indicator assess whether the respondent has successfully established himself in a legitimate life in society so that the attraction of a legitimate way of life far outweights the attraction of illegal pursuits. The items which measure this indicator are:

\footnotetext{
"A person like myself hasn't much to lose by committing a criminal offence." "Money is the only reason to have a job."

"A person should never stop trying to get ahead."
}

Responses to these questions were on a seven point agreedisagree continuum. Low reliability coefficients (Alpha =.09 in the pre-test and .03 in the post-test) suggest that we 
cannot have any confidence that these indicators are in fact measuring "stake in conformity". This will have to be considered in the interpretation of the findings. The third indicator is the inmate's expectation of the amount of help he will receive from family, friends and employers and the quality of his relationships with these people after he is released from prison. The four items which measure this are:

"Do you think that members of your family will do what they can to help you when you get out?'

"Do you think that your old friends will want to go around with you after you get out?"

The response categories for these questions are:

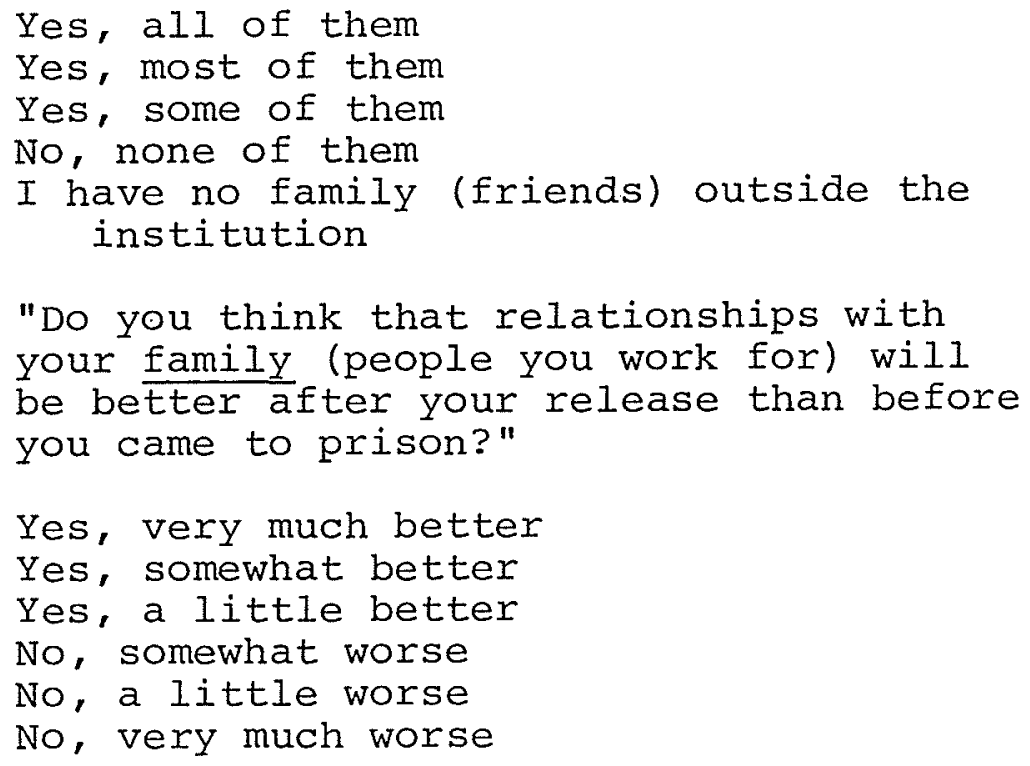

The reliability coefficients for these items are Alpha $=.50$ 
for the pre-test and .78 for the post-test. Again low reliability coefficients suggest that these items are probably not measuring the same thing and that we cannot tell what, if anything, they are measuring when they are combined in an index. These items will be analyzed separately.

The fourth indicator of "bonds with others" is bonds with family members. The following items measure the importance an inmate places on his relationship with his family and his perception of their trust in him:

"Nothing in Iife is worth the sacrifice of losing contact with my family."

"My family was confidence in me."

The response categories for these items are on a seven point agree-disagree continuum.

The last indicator which will be measured is orientation to criminal means. The following items were used to develop an index:

"A man should always obey the laws, no matter how much they stand in the way of his ambitions."

"It's alright for a person to break the law if he doesn't get caught."

"It's alright to 'get around' the law if you don't actually break it."

"A hungry man has the right to steal."

"A man's a fool to work for a living if he can get by some other way." 
"It is difficult to break the law and keep one's self respect."

Responses to these items are on a seven point agree-disagree continuum. The reliability coefficients for this index are Alpha $=.73$ for the pre-test and Alpha=.70 for the post-test.

$\underline{\text { Results }}$

The first indicator of "bonds with others" is criminal identification. Analysis of variance between the B.C. Penitentiary experimental and control groups was computed for each item and no significant differences were evident in either the pre-test or the post-test.

Inmates were classified as being either high or low in criminal identification according to the number of items in which the inmate's response indicates identification with lawbreakers or law-abiders (Table 13). The findings indicate that participation in the program did decrease the proportion of inmates who were classified as high in criminal identification, however, the difference between the experimental and control groups is not statistically significant. The proportion of inmates classified as high on criminal identification decreased from $13.3 \%$ to $0 \%$ in the B.C. Penitentiary experimental group and increased from $9.1 \%$ to $36.4 \%$ in the control group. At Matsqui there was also a decrease in the proportion of inmates in the experimental group who were classified 
as high on criminal identification. This decrease was from 8. 3 \% to $0 \%$

Although these differences are not statistically significant, the fact that the proportion of inmates who were classified as high on criminal identification in both prisons decreased in the experimental groups while it increased in the B.C. Penitentiary control group may suggest that the program had some effect on inmates reference group orientation. However, when these items were combined to form an index they had low reliability coefficients in both the pre-test and the post-test. Because of this we cannot have confidence that these findings are valid.

The second indicator of reference group orientation is inmates' associational preference. Analysis of variance was completed for each item in the index as well as for the index itself. Only one significant difference was found for the items in the pre-test. The B.C. Penitentiary groups had significantly different responses at the .0285 level to the following item: "I don't care to associate with the kind of people that are in prison." While the control group tended to disagree with this statement the experimental group tended to agree with it. In the post-test there was also only one item which was statistically significantly different between the experimental and control groups. This item was: "I want to keep in touch with inmates I met here after I get out." 
The findings indicate that the experimental group tended to disagree with the statement while the control group tended to agree. This difference was statistically significant at the .0097 level of confidence.

An index of criminal association preference was developed and these data were analyzed (Table 14). The results from this index suggest that participation in the program is negatively associated with criminal association preference. At B.C. Penitentiary no significant differences appeared between the groups in the pre-test, however, the post-test the difference did approach statistical significance (F Probability=.0534). The mean score for each group indicates that the control group preferred to associate with criminals to a greater extent than did the experimental group. In summary, the findings from both of the items that measure inmates' reference group orientation suggest that participation in the program may cause an inmate to identify less with a criminal reference group and more with conventional society. The second indicator of "bonds with others" is stake in conformity. The findings from the first item do not show any evidence that prison education affects inmates' stake in a conventional life style (Table 15). Inmates were asked to agree or disagree with the following item: "A person like myself hasn't much to lose by committing a criminal offence." At the B.C. Penitentiary $78.6 \%$ of the experimental group 
disagreed with this item in the pre-test while $92.9 \%$ did so in the post-test. In the control group $70.0 \%$ disagreed in the pre-test while $80.0 \%$ did so in the post-test. At the Matsqui Institution $91.7 \%$ of the experimental group disagreed with the item in the pre-test while $100 \%$ did so in the posttest. These findings indicate that the large majority of inmates in all groups felt they had something to lose by committing a criminal offence, and that the proportion who felt this way increased from the pre-test to the post-test in all groups.

The findings from the second item - "Money is the only reason to have a job" - are ambiguous (Table 16). Disagreement with this statement indicates that the individual agrees that one can get more out of a job than simply monetary reward. This may include such things as personal satisfaction, a means of realizing long-term goals, as well as a means of obtaining and maintaining a respectable position in society. In the pre-test $21.3 \%$ of the B.C. Penitentiary experimental group and $30.0 \%$ of the control group agreed that money was the only reason to have a job. In the post-test $7.1 \%$ of the experimental group and $30.0 \%$ of the control group thought this way. This indicates that in the experimental group there was a decrease from the pre-test to the post-test in the number of inmates who believed that money is the only reason to have a job while in the control group there was no 
change at all. In the Matsqui experimental group there was a slight increase in the number of inmates who disagree with this statement. Seventy-five percent disagreed in the pretest compared with $83.3 \%$ in the post-test. These findings indicate that participating in the program did not have any effect on the inmates' attitudes concerning the reasons for having a job, but they do indicate that the large majority of inmates feel that there are other reasons besides money for having a job.

The final measure of "stake in conformity" is the item: "A person should hever stop trying to get ahead." Again, the findings are ambiguous and the differences are not significant (Table 17). The proportion of inmates who agreed with the statement decreased from the pre-test to the posttest for both the B.C. Penitentiary and the Matsqui experimental groups, while in the B.C. Penitentiary control group none of the inmates agreed with this statement in either the pre-test or the post-test.

In summary, the findings from these three items do not indicate that participation in a prison education program influences inmates' stake in not committing further crimes or his attraction to conventional pursuits. The next item measures whether the inmate is aware of or has feelings of commitment to a conventional lifestyle.

Each inmate was asked what he thought were his 
chances of being returned to prison in the future (Table 18). The findings from these data indicate that during the program inmates in both experimental groups as well as the control group tended to become more optimistic about their chances of avoiding future penitentiary sentences. In the pre-test 14.3\% of the B.C. Penitentiary experimental group said they thought they had no chance of returning to prison in the future compared with $21.4 \%$ in the post-test. In the control group $10.0 \%$ felt this way in the pre-test compared with $40.0 \%$ in the post-test. In the pre-test at Matsqui $16.7 \%$ of the experimental group thought they had no chance of returning to prison while $33.3 \%$ thought this way in the post-test.

In summary, the findings suggest that most inmates do have a "stake in conformity", but that it was not affected by the education program. Generally they feel that they have something to lose by committing a criminal offence and that there are other reasons besides money for having a job. In contrast, they do not agree that "a person should never stop trying to get ahead." Contrary to expectations the data did not show that participating in the program increased the inmates' stake in conformity, nor did they indicate that participating in the program affected inmates' feelings or awareness of their commitment to conformity. The third indicator of "bonds with others" is inmates' expectations of the amount of help they will receive 
from family, friends and employers and their relationships with these people after they are released from prison. The findings seem to suggest that participation in an education program does improve inmates' expectations concerning postprison relationships, however, this evidence is very weak. There were two items which measured an inmate's expectations concerning his relationship with his family after his release. The first item asked whether he thought his family would help him out after his release (Table 19). While there were no statistically significant differences between the groups on this item, there was a trend which should be noted. Both the B.C. Penitentiary and the Matsqui experimental groups were slightly more optimistic about future help from their families in the post-test than they were in the pre-test while the reverse was so for the B.C. Penitentiary control group.

The second item dealt with inmates' expectations concerning the quality of their relationships with their families after they are released from prison (Table 20). The findings for this item are consistent with the findings discussed above. While the B.C. Penitentiary control group inmates had lower expectations concerning the quality of their relationships with their families in the post-test than in the pre-test, both of the experimental groups had higher expectations. The difference between the B.C. Penitentiary control and 
experimental groups was statistically significant at the .01 level of confidence. These findings seem to suggest that participating in the education program did improve inmates' expectations as to the quality of their relationships with their families after they are released.

The third item which measured post-prison expectations was concerned with whether the inmate thought his old friends would want to associate with him after his release from prison (Table 21). There were no significant differences between the B.C. Penitentiary experimental and control groups in either the pre-test or post-test. One problem with this item is that it does not distinguish between deviant and conventional peers. It may be that deviant peers or friends who have been involved in criminal activities would be more willing to associate with an ex-convict than would conventional peers or friends who do not make a habit of being involved in criminal activities. To test this hypothesis inmates were classified as having either mostly conventional or mostly deviant peers. These two categories were then compared in terms of their responses to the question concerning whether he thought his friends would go around with him after his release. The type of friends an inmate had was determined by the following item:

\footnotetext{
"Most of my friends on the outside always seem to be getting into trouble with the police."
} 
On a seven category agree-disagree continuum, inmates who agreed with this item were classified as having deviant peers while those who disagreed were classified as having conventional peers.

The results, reported in Tables $22 \mathrm{a}$ and $22 \mathrm{~b}$, so seem to support this hypothesis although the findings are not statistically significant. Inmates in all three groups in both the pre-test and post-test who were classified as having deviant peers were more likely to say that all or most of their friends would want to go around with them after they were released from prison than were inmates who had conventional peers. In summary, it seems that inmates who have deviant peers expect to receive support from more of their friends after they are released than do inmates who have conventional peers.

The last item has to do with the inmates' expectations of their relationships with their employers after they are released (Table 23). There are no significant differences between the experimental and control groups in the pre-test, however, statistically significant differences did occur in the post-test between the B.C. Penitentiary groups. In the pre-test $50.0 \%$ of the B.C. Penitentiary experimental group compared with $71.5 \%$ of the control group said they expected to have a "better" relationship with their employers than they had previous to entering prison. In the post-test $78.6 \%$ 
of the experimental group compared with $28.6 \%$ of the control group had these expectations. This difference was statistically significant at the .01 level of confidence.

The findings from the Matsqui experimental group are consistent with the findings from the B.C. Penitentiary experimental group. In the pre-test $18.2 \%$ said they expected their relationships with people they work for to be "much better", compared with $54.5 \%$ in the post-test.

While these findings are not in anyway conclusive, there is evidence to suggest that post-prison expectations may be favorably affected by participation in the program. Significant differences did appear in the post-test for the B.C. Penitentiary groups on two of the items which measured their expectations concerning their relationships with their family and employers after they were released from prison. While the lack of a control group at Matsqui makes it difficult to draw any conclusions about the effects of the program on inmates in that institution, it is significant that the findings from the experimental group are consistent with the findings of the B.C. Penitentiary experimental group. The fifth indicator of "bonds with others" is the bonds an inmate has with the members of his family. The findings may suggest that participation in the program increases the importance of the inmate's family bonds to him. Again, these findings are tenuous and ambiguous and therefore 
must be interpreted cautiously. The results of the first item - "Nothing in life is worth the sacrifice of losing contact with my family" - are statistically significant for the B.C. Penitentiary groups (Table 24 ). In the pre-test $73.3 \%$ of the experimental group agreed with this statement compared with $50.0 \%$ of the control group. In the post-test again $73.3 \%$ of the experimental group agreed with this while only $20.0 \%$ of the control group did. This difference was statistically significant at the .006 level of confidence. The results from the Matsqui experimental group are consistent with these findings. In the pre-test $33.3 \%$ agreed with this statement compared with $50.0 \%$ in the post-test.

The second item used to measure an inmate's bonds with his family was: "My family has confidence in me". While there were no statistically significant differences between the B.C. Penitentiary groups, the findings for the B.C. Penitentiary are in the predicted direction (Table 25). Fifty-seven point one percent of the experimental group agreed with this item in the pre-test while $71.4 \%$ did so in the post-test. In the control group $40.0 \%$ agreed in both the pre-test and the post-test. This indicates that in the experimental group more inmates felt their family had confidence in them in the post-test than in the pre-test, while in the control group there was no change. The findings from the Matsqui experimental group are not consistent with these 
findings. In the pre-test 58.3\% felt their families had confidence in them compared with $49.9 \%$ in the post-test.

The final indicator of "bonds with others", is an index of orientation to criminal means. Analysis of this data does not suggest that participation in the education program affects an inmate's bonds. Analysis of variance was carried out for each item, comparing the B.C. Penitentiary experimental and control groups in the pre-test and the posttest and no statistically significant differences were found. Similarly, when the items were combined into an index there were no statistically significant differences between the B.C. Penitentiary groups in either the pre-test of the posttest (Table 26).

Discussion of the Findings

Control theory suggests that ties to deviant peers, especially in the absence of conventional ties to peers and adults, will be conducive to deviancy. This has implications for rehabilitation programs because it suggests that inmates have to augment or develop strong relationships with conventional others before rehabilitation can be successful. It is obvious that this is not an easy task in the prison setting where inmates are constantly exposed to deviant others and are prevented from having much contact with conventional society. The effect of confinement to a prison is most 
notably that of destroying or weakening conventional bonds and strengthening deviant bonds.

It has been hypothesized in this thesis that a prison education program can increase the bonds inmates have with conventional society and decrease their criminal bonds. The findings do seem to support this hypothesis. However, few of the findings were statistically significant and there was much ambiguity. Inmates who participated in the program had higher post-prison expectations in the post-test than did inmates in the control group, and they valued their relationships with family members more. There were statistically significant differences between the B.C. Penitentiary groups in the post-test on three of the six items which measured these indicators. Participation in the program was also associated with a slight decrease in criminal identification and criminal association preference as well as a broader outlook on the purposes of a career and a greater awareness of having a stake in conformity. 


\section{Chapter 5}

Impact of the Program on Recidivism

Recidivism is the measure most commonly used to assess the effectiveness of correctional programs. Martinson et al. (1976) state that the overcrowded conditions of our prisons are not conducive to rehabilitation. Many experts on prison life call for the abolition of prisons, arguing that many features of prison constitute cruel and unusual punishment (Toch, 1981). However, pressures exerted on judges and legislators by the public to "keep our neighborhoods safe" have contributed to the ever-increasing intake levels of our prisons. As a result, the potential of finding some method by which the recidivism rates of prisoners can be reduced is of ultimate concern to legislators.

In addition to the pressures put on legislators to lock up those "undesirables" who violate the laws, there are also pressures to make prisons more humane and less stressful. As a result most prisons now offer social services of some form to inmates (Griffin, 1978). Of course, the reformation of prisons was not simply to make the time an inmate spends in prison more tolerable, of more concern was the potential of such actions reducing the recidivism rates and thus reducing the expense of our ever-expanding correctional system (Toch, 1981). 
Such concern with recidivism rates explains why most evaluations of prison education programs concentrate on inmates' criminalistic behavior after completing the program as opposed to the program's ability to educate inmates. The effect of an education program on criminal behavior is obviously not a direct one: Many possible intervening variables have been identified in the literature to explain this hypothesized effect. Parlett (1974) contends that these intervening variables can be separated into two major categories, each representing a different view on the goal of education in general. Hie describes these different philosophies as "education for values" and "education for production". In the first education plays the role of transmitting the attitudes and values necessary for the recipient to adjust to society. In the second, education plays the role of increasing the employability of an inmate following his release. These two views are not mutually exclusive.

Employment is important to the ex-inmate for economic as well as "extra-economic" reasons. Research by Liker (1982) shows that post-prison adjustment is partly affected by post-prison employment experiences. The findings of this study show that ex-inmates who were employed tended to experience less emotional distress during the post-prison transition than those ex-inmates who were not employed. While the economic benefits of having a job play a major part in 
reducing stress during the transition phase, "extra-economic" benefits also enhance the effective well-being of employed ex-inmates. While the findings did not specify what these "extra-economic" benefits are, literature in this area lead the researchers to assume they would include such things as "self-respect, social contacts, and structured activity" (Liker, 1982:281).

While it is important to determine the effects the program had on recidivism rates, it is just as important to determine what these intervening variables are which are influencing the relationships. Possible intervening variables which will be examined in this thesis are prisonization, social bonds, certain biographical variables, and orientation to rehabiliation. As well, the type of problems inmates encountered once they were released and their personal longterm plans will be examined in respect to post-release success.

Hypothesis 3: Inmates in the experimental groups will have a lower recidivism rate than inmates in the control groups. Measurement of the Variables

The major difficulty in testing this last hypothesis is constructing a measure of recidivism. A review of pertinent literature shows that recidivism has been 
operationally defined in many very different ways. Moberg and Ericson (1972) suggest that an objective measure of recidivism must consider that there are various degrees of success and failure. That is, the rehabilitation of offenders most often involves a series of gradual steps rather than a sudden and complete one-step reformation. For this reason recidivism will be measured using Glaser's (1969) four-fold classification system:

Clear Reformation - the individual has not committed any further known crimes, has a steady job or is attending school regularly, and has avoided the company of criminal associates.

Marginal Reformation - has not returned to prison but has no legitimate occupation, has been involved with minor offences, or habitually associates with individuals who have known criminal records.

Marginal Failure - has been returned to prison for minor crimes or technical violations of parole regulations.

Clear Recidivist - has been returned to prison for committing a major offence.

As mentioned previously the intervening variables which were measured include: prisonization, social bonds, certain biographical variables, and orientation to rehabilitation. The measures of prisonization and social bonds are the same as those which were used in testing the first two hypotheses. The biographical variables which were measured include: age, length of present sentence, length of time served, alcoholism, 
drug use, type of offence committed, period of employment after release, and type of job obtained after release. The types of offences inmates were currently serving time for were categorized as drug offences, property offences, fraud and crimes against persons.

Information concerning period of employment and type of job was obtained from the follow-up interview. Period of employment was categorized on a seven point continuum ranging from not employed to employed more than 75\% of the time. Type of job obtained was grouped under the following categories: manual work, white collar and self employed. As well, a category was added to include those inmates who were on welfare or unemployed.

Unfortunately there is no direct measure to determine whether an inmate was oriented towards rehabilitation. The measures which have been selected to indicate this variable assess the inmate's perception of the institutions goals. Each inmate was asked to indicate the importance of each of the following goals:

"To change the feelings or attitudes of the inmates so they can understand themselves better."

"Topunish men who have violated the law so they will not do it again."

"To provide training in discipline so that inmates will learn to do what others want them to do." 


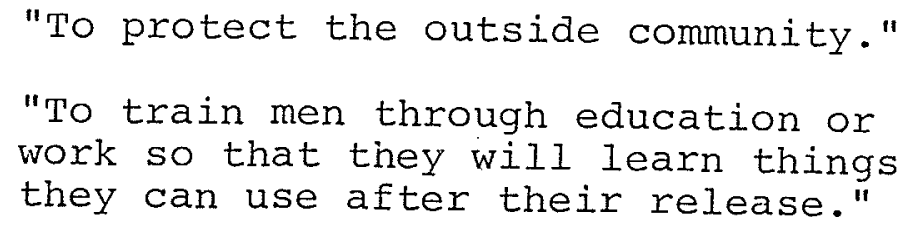

Responses to these questions are on a seven point continuum ranging from very important to not at all important. It is expected that inmates who are oriented towards rehabilitation will assign most importance to the first and the last goal while those who are not will assign most importance to the second, third and fourth goals.

The type of post-release problems inmates encountered and their long-term plans were measured by the following open-ended questions in the follow-up questionnaire: "Describe the sorts of problems which you
encountered on release."

"Do you have any long-term plans?"

\section{$\underline{\text { Results }}$}

The information which was necessary to determine the success or failure an inmate had in avoiding criminal activities after his release from prison was obtained from the follow-up interviews as well as from the Federal Penitentiary Services records. Unfortunately, the length of time between release and follow-up interviews varies because the inmates were released over a period of almost three years. It had been planned to have most of the inmates released 
over a relatively short period of time and to carry out followup interviews two years after release, however, political constraints placed on the Parole Services interfered with these plans. Although the length of time between release and followup interviews varied, it was similar for the experimental and control groups at each institution. For the B.C. Penitentiary groups, the time interval averaged 18.6 months for the experimentals and 20.6 months for controls, while for the Matsqui groups the averages were 34.9 months for experimentals and 31 months for controls. The average time between release and the final follow-up in July, 1980, was 77 months for B.C. Penitentiary experimentals, 80 months for B.C. Penitentiary controls, 81 months for Matsqui experimentals and 82 months for Matsqui controls.

The analysis was also complicated by the fact that follow-up interviews could not be carried out with a number of the inmates. Two inmates (both from the B.C. Penitentiary control group) were deported back to the United States following release, and several others rather quickly dropped out of sight. In total, 47 of the 60 inmates who remained in the experimental and control groups were interviewed. Postrelease information was obtained on an additional 11 inmates from the files of the Federal Penitentiary Services. Co-operation with the follow-up was greatest among members of the experimental groups. Information concerning the post- 
release activities of all of these inmates was obtained. Data were not obtained concerning 3 of the 17 inmates in the B.C. Penitentiary control group or concerning 1 of the 13 inmates in the Matsqui control group.

In Table 27 , the results of the reciaivism analysis are shown. For the Matsqui groups there was little difference between them. Though the experimentals did have somewhat more success than did the controls, this difference was small and was not statistically significant. The B.C. Penitentiary program was somewhat more successful. While the differences between the experimental and control groups are not statistically significant, there is a slightly higher rate of success among the experimentals.

The finding that the B.C. Penitentiary experimental group was more successful than the Matsqui experimental group was not totally unexpected because overall the B.C. Penitentiary program was considered to be more of a success than was the Matsqui program. It was mentioned earlier in this thesis that the researchers who carried out the project judged that the B.C. Penitentiary program was less afflicted by the daily activities of the institution than was the Matsqui program. The interpretation of these results is very difficult because there are few data available on recidivism rates, either from other programs or for the general prison population, with which to compare these findings. It may be argued 
that while the differences (13.9\% and $5.8 \%$ ) are not large, they are consistent and the magnitude of the difference between the B.C. Penitentiary groups is comparable to that found in many of the programs classified as successful in the research review carried out by Gendreau and Ross (1979). Another just as convincing argument is that the differences between the experimental and control groups are not statistically significant and that to provide more resources for such programs is not practical. In light of the fact that the results from the B.C. Penitentiary program do suggest that the program had an effect on recidivism rates despite the short duration of the program (5 months) in combination with the extensive educational deficiencies of the students, and the sometimes long period of time between completion of the program and the inmate's release, it does seem possible that well designed and implemented prison education programs can have a positive impact on recidivism rates. This will be discussed further in the concluding chapter.

$$
\text { To complete this evaluation of recidivism rates, }
$$
several possible intervening variables were cross-tabulated with the four-fold success-failure classification system. The results are reported in Table 28. Unfortunately, for many of the variables the cases are not distributed very evenly among the categories in the contingency tables. As a result, some of the cells have none or only one case. This 
causes the gamma's computed to be artifactual because the distribution of cases is the basis on which the description of the strength of the relationship is constructed. The gammas which are suspected of being artifactual have been indicated in the table. As can be seen, very few of the indicators are related to the dependent variable, post-release success, in the predicted direction. Of the 38 indicators tested, 15 are in the predicted direction and of these II are suspected of being artifactual.

None of the measures of prisonization were related to post-release success in the predicted direction. Two of the items: "I would share my food and cigarettes: (I) with no one (2) only with my close friends (3) only with inmates that I know well (4) with any inmate" and "When I'm released I would be willing to invite into my home: (1) no one who has ever done time (2) only those inmates that I know well (4) any inmate" - have fairly strong negative relationships with post-release success. This suggests that inmates who express solidarity by stating that they will share food and cigarettes with any inmate and will invite any inmate into their home once they are released tend to be more successful than those who do not express this high degree of inmate solidarity. Although these relationships are not in the predicted direction, they do lend support to the contention expressed earlier in this thesis that the nature of the 
program may have lead inmates in the experimental group to respond to the questions in a manner which was measured as expressed solidarity when in fact what was actually reflected was the intensity and quality of relationships the inmates in the program had established with each other.

Various dimensions of inmates' social bonds were measured. Several of these items appear to be related to post-release success in the predicted direction. Contrary to expectations, inmates who had a conventional reference group orientation as measured by a low score on criminal identification and criminal association preference did not have more post-release success than those who had criminal reference group orientation. Both of these items had a negative relationship (-.24324 and -.37809 respectively) with postrelease success.

Two of the four items which measured inmates' "stake in conformity" were related to post-release success in the predicted direction. Unfortunately one of these had a potentially artifactual relationship with the dependent variable because of the distribution of cases and the other has a very weak relationship.

The findings relating to post-prison expectations suggest that the more positive expectations an inmate has the better success rate he will have after release. Of the four items which measured this indicator, three were in the 
predicted direction. These included his expectations of receiving help from his family and his expectations of his relationships with family members and employers. It must be noted, however, that all of these three gammas are potentially artifactual because of the lack of distribution of cases within the cells of the contingency tables. The only item that wasn't in the predicted direction referred to whether the inmate's old friends would want to associate with him after release. This is actually not so surprising because if the inmate had conventional friends, as opposed to deviant friends, he may not expect them to associate with him because of the stigma attached to a criminal record. In contrast an inmate with deviant friends would expect them to want to go around with him after his release, and we could expect that his chances of getting reinvolved are high. It seems then that inmates who have positive expectations concerning their relationships with family and employers after release are more able to avoid reinvolvement than those who do not have such expectations.

One of the three items which measured bonds with family members is related to post-prison success in the predicted direction, however, all three of the items have such a poor distribution of cases in the cross-tabulation that the gammas are suspected of being artifactual. The item which is related in the predicted direction is "My family has 
confidence in me." This item is positively related to postprison success.

of the biographical variables, two have substantial relationships with post-release success in the predicted direction. These are drug use and period of employment after release. The data pertaining to drug use clearly indicate that inmates who were drug addicts when they entered prison have higher recidivism rates than those who were not. Table 29 shows that of those inmates who were classified as having post-release success $16.7 \%$ were drug addicts while $46.7 \%$ had no drug use. In contrast, $70.8 \%$ of the recidivists were drug addicts and $53.3 \%$ of them had no drug use. This finding is not unexpected because drug addicts have high recidivism rates. What is surprising is the positive relationship which was found between alcoholism and post-release success. While the strength of this relationship as indicated by gamma is potentially artifactual because of the distribution of the cases, a review of the cross-tabulation table (Table 33) reveals that a greater proportion of the inmates in the clearly reformed group were alcoholics as opposed to nonalcoholics. The opposite is so for the clear recidivist group with a higher proportion of these inmates being nonalcoholics. It was suspected that these findings were the result of alcohol and drug use not being mutually exclusive categories. That is, an inmate may be classified as an 
alcoholic, a drug addict, both or neither. As a result, inmates who were drug addicts may be classified as nonalcoholics and his drug addiction would affect his postrelease success, not his non-alcoholic state. To test this, alcohol use was cross-tabulated with post-release success controlling for drug use and drug use was cross-tabulated with post-release success controlling for alcohol use. The results, shown in Tables 31 and 32 do not support this claim. The relationship between alcoholism and post-release success remains positive and the relationship between drug addiction and post-release success remains negative. There does not appear to be a logical explanation for these findings. Period of employment after release seems to have a strong relationship with post-release success, however, it should be noted that this gamma has been found to be potentially artifactual because of the small number of cases it is based on. The cross-tabulation table (Table 33) does suggest that the relationship exists, however, the strength of the relationship seems to be inflated. Inmates who were employed for a long period of time are more successful in avoiding criminal activities than those who were employed for a short period of time. Thirty-eight point seven percent of those classified as successful were employed $75 \%$ of the time or more while $10.0 \%$ were employed for only $25.0 \%$ of the time or less. In contrast, $58.1 \%$ of the recidivists were 
employed for $75.0 \%$ of the time or more as compared to $80.0 \%$ who were employed for only $25.0 \%$ of the time or less. The data do suggest that period of employment has a positive impact on recidivism rates.

The indicators of orientation to rehabilitation suggest that the more importance an inmate places on the institutional goals of punishment and training in discipline, the less post-release success he has. To state this in a different way, inmates who are not oriented towards rehabilitation have less post-release success. Of the five items included to measure this variable, four are related in the predicted direction, however, three of these are considered to be potentially artifactual. This variable will be analyzed in more detail at this point.

The findings pertaining to inmates' orientation to rehabilitation somewhat support the hypothesis that participation in the program aids inmates in self understanding and brings about changes in their attitudes, however, this is only so for the B.C. Penitentiary inmates, and none of the differences between the experimental and control groups are statistically significant. The findings shown in Table 34 indicate that in the pre-test the B.C. Penitentiary experimental group attributed most importance to the goal of providing training in discipline while the control group attributed most importance to the goal of protecting the 
outside community. In the post-test the experimental group attributed most importance to the goal of changing the feelings or attitudes of the inmates and second most importance to the goal of training men through education or work while the control group again rated the goal of protecting the outside community as most important. It should be noted that the two goals the experimental group indicated as most important in the post-test are the goals which indicate an orientation to rehabilitation.

At the Matsqui Institution the findings are quite different from those at the B.C. Penitentiary. In the pretest the Matsqui experimental group attributed most importance to the goal of changing inmates' feelings or attitudes while the control group attributed most importance to the goal of training men through education or work. In direct contrast to expectations, the goal deemed most important by the experimental group in the post-test was that of protecting the community while again the control group attributed most importance to training men through education or work. It is apparent that the findings for the B.C. Penitentiary and the Matsqui Institution are very different. The inmates at B.C. Penitentiary who participated in the program seemed to develop an orientation towards rehabilitation, however, at Matsqui it seems that the inmates were oriented towards rehabilitation when they volunteered to participate in the 
program and that participation in the program weakened this orientation if it affected it at all. These findings show that the program had more effect on the attitudes and feelings of the B.C. Penitentiary inmates than it did on the Matsqui inmates. They also reflect the overall greater success of the B.C. Penitentiary program.

The effect inmates' orientation to rehabilitation had on their recidivism rate was also determined. These findings, shown in Table 35, suggest that inmates who are oriented towards rehabilitation are more successful in avoiding contact with the law after release. More of those inmates who are classified as clearly reformed indicated that they felt the institutional goals of changing the feelings and attitudes of inmates and training them through education and work were more important than any of the other goals in both the pre-test and post-test. As well, the proportion who responded this way increased in the post-test. The proportion who felt the goal of changing the feelings and attitudes of the inmates was important increased from $53.8 \%$ to $84.6 \%$ and the proportion who felt the goal of training men through education and work was important increased from $53.8 \%$ to $76.9 \%$. The significance of this finding is that it indicates that most of those inmates who avoided contact with the law after release had more of an orientation towards rehabilitation when the project ended than when it began. 
Inmates who were classified as clear recidivists may have had somewhat of an orientation towards rehabilitation in the pre-test, however, this was not evident in the post-test. In the pre-test the greatest proportion of inmates (60.9\%) indicated that they felt the goal to train men through education and work was most important while in the post-test they felt the goal of protecting the outside community was (78.3\%).

In summary, the findings pertaining to inmates' orientation to rehabilitation suggest that participation in the education program may change the attitudes and feelings of inmates and orientate them more towards rehabilitation. The significance of this finding is enhanced by the finding that inmates who are successful in avoiding contact with the law after release are those who place more importance on the institution's rehabilitation goals, or those who have an orientation towards rehabilitation.

The data pertaining to the type of problems inmates encountered once they were released from prison (Table 36) show that many inmates in all of the categories of postrelease success encountered problems, however, those who were classified as clear recidivists did profess to have more problems than those who were classified as clearly reformed. The most common problem for inmates in both of these categories was in the area of personal and emotional adjustment. This includes problems such as being socially 
withdrawn, having "bad nerves" and the inability to cope with simple everyday problems. Of those inmates in the clearly reformed group who stated that they had problems, $66.7 \%$ said they had personal adjustment and emotional problems compared with $72.0 \%$ of those in the clear recidivist category. Interpersonal problems was the second major type of problem for inmates who were classified as clear recidivist while for those who were reformed it was lack of employment. It seems that inmates who were classified as clearly reformed did not have as many problems with their relationships with friends and Iamily as those who were recidivists. Of the recidivists who had post-release problems, $56.0 \%$ stated they had interpersonal problems compared with $33.3 \%$ of the reformed. The only type of problem those in the reformed group complained of more than those in the recidivist group was difficulties finding a job. Fifty percent of the reformed who had problems stated that this was a problem for them compared with $36.0 \%$ of the recidivists although this finding may be reflecting the proportions of inmates in each category who actually attempted to find employment. The last two types of problems are alcohol and drug problems and the stigma attached to being an "ex-con". The proportions of inmates who had drug or alcohol problems was very similar for the reformed and the recidivists. The proportions are $25.0 \%$ and $36.0 \%$ respectively. The stigma attached to being an ex-convict was cited as a problem by 
$28.0 \%$ of the recidivists who had problems compared with $8.3 \%$ of the reformed group. Problems of this type included being hasseled by the police and others and being labelled as an "ex-con" forever.

In summary, it seems that inmates who recidivate tend to encounter more post-release problems than inmates who are considered to be reformed. While a large proportion of inmates in both groups stated that they had personal and emotional adjustment problems, this was somewhat more of a problem for the recidivists than it was for the reformed group. As well, more inmates classifies as recidivists had problems in the areas of relationships with others, drugs and alcohol abuse and general hassling because of stigma attached to being an ex-convict than did those inmates classified as reformed.

The findings pertaining to inmate's long-term plans show that slightly more inmates in the reformed group had long-term plans than those in the recidivist group. of those inmates for whom a follow-up interview was obtained, 83.3\% of the reformed group, $66.7 \%$ of the marginal recidivist group and $75.0 \%$ of the clear recidivist group said that they had long-term plans. This item was answered by 12 of the 16 inmates in the reformed group, 3 of the 4 in the marginal recidivist group and 28 of the 38 in the clear recidivist group. The nature of these plans does not seem to vary 
between the different classifications (Table 37). The most common plan for inmates in both groups concerned finding a job. This included $90.0 \%$ of the reformed inmates and $90.1 \%$ of the recidivists who had a long-term plan. More inmates in the recidivist group tended to have family oriented plans, such as spending more time with their families or getting married, than did the reformed group. Family oriented plans were stated by $52.4 \%$ of the recidivists compared with $40.0 \%$ of the reformed. A possible explanation for this may concern basic differences between the groups in terms of the quality of their family life prior to their imprisonment. It may be that those inmates who were classified as reformed were not interested in family-oriented plans because their prior family experiences were not very good and they wished to disassociate themselves from unrewarding relationships. In contrast, it may be that those who were classified as recidivists who also had negative experiences with family relationships, do not realize that it is possible to have any other type of relationship with others. It could be that the disappointment experienced by these inmates when their family-oriented plans did not work out is related to their post-release behavior and eventual return to prison. Other types of long-term plans included education, staying off drugs and staying out of prison. The only difference worth nothing is that the only group to state staying off drugs as 
a long-term plan was the clear recidivist group (9.5\%).

Discussion of the Findings

There is evidence to suggest that inmates who participated in the education program had lower recidivism rates than inmates in the control groups. While the differences are small they should not be ignored. If positive results can be obtained from a five-month program, carried out under less than ideal conaitions with educationally deficient students, it leads one to speculate as to what impact a well-designed and carried out program could have. While the results from the Matsqui program were not as encouraging as were those from the B.C. Penitentiary program, they were positive. There were many variables which affected the outcome of the Matsqui program causing it to be less successful in rehabilitating inmates than the B.C. Penitentiary program. These included less co-operation from the custodial staff and competition with other institutional activities. Despite the problems encountered at both of these institutions the findings do suggest that the education program may have positively affected recidivism rates.

The task of isolating the intervening variables which explain this positive effect was complicated by the small number of cases. This created methodological problems so that the findings are not undisputable. Despite this, the 
data do suggest that there are certain variables which interact with the education program to make to more effective in rehabilitating inmates. First of all, inmates who have positive post-prison expectations have lower recidivism rates. This includes expectations of receiving help from their family and having good relationships with family members and employers. As well, inmates who feel their family has confidence in them have lower recidivism rates. The types of problems encountered by inmates once they are released from prison also seems to be related to post-release success. Specifically, inmates who do not have interpersonal or emotional problems tend to have lower recidivism rates.

Drug use and post-prison employment are also important indicators of post-release success. Inmates who were drug addicts had much higher recidivism rates than nonaddicts. A very important piece of information obtained from this study is that the longer the period of time an inmate is employed after release the lower are his chances of returning to prison. This is important because it emphasizes the necessity of continuing to provide inmates with job skills and assistance in obtaining employment after release.

The last variable which appears to enhance the success of the education program is orientation to rehabilitation. The data suggest that the education program may lower the recidivism rates of inmates by causing them to 
become more orientated towards rehabilitation. This is a very significant finding when you consider the short duration of the program and the complexity involved in changing a person's feelings and attitudes. 


\section{Chapter 6}

Conclusion

The current debate in the Iiterature concerning the effects of rehabilitation programs in correctional institutions has been perpetuated by the pausity and rather dismal quality of evaluation studies that have been carried out in this area. While methodological problems often reduce the conclusions reported by these studies to little more than speculation, it is probably safe to say that no consistently positive affects have been observed that can be attributed to prison education programs.

The Donner Project was designed and implemented so as to avoid the methodological problems for which other evaluation studies have been critized. The pre-test, post-test design allows for comparisons over time, and the control group allows us to discount those changes which were not caused by the program. This project was also unique in that inmates' total involvement in the project was ensured by having an instructor in the classroom all day. As well, the instructors encouraged inmates to discuss and debate issues. This intense teacher-student contact whould help to keep students' interest up and thus keep the dropout rate down. It should also be noted that this project was a university "progrant in the sense that the courses offered were fully accredited and could lead to a degree. Often what is 
referred to as a university education "program" is simply a course that is offered that does not lead to anything. It is also common for these programs to have an instructor come into the institution only once or twice a week to deliver a lecture. Placing high demands on inmates, both in terms of time and effort, is important to ensure the program's ability to break down the barriers to rehabilitation which exist within the social organization of the prison as well as in society. These barriers will be discussed later in this chapter. In summary, the design of this evaluation study and the intensity of the education program suggest that the Donner Project does improve the state of evaluation research, and the findings of this study are more reliable than the findings from most other studies in this area.

Unfortunately, this study experienced some difficulties that may somewhat bias the findings. Some of these problems involved hostility from the custodial staff, but perhaps the most serious problems were the attrition rate of the control groups and the inability to obtain follow-up interviews with all of the inmates. The attrition rate of the control groups is mostly accounted for by transfers to other institutions and refusals from these inmates to participate in the post-test. It is common in penal institutions for inmates to be transferred to other institutions of a reduced security level. Inmates in the experimental groups 
had to agree to forego transfer as a condition of their acceptance into the program. The second major problem encountered by this study, that of following-up all of the inmates after their release, was somewhat compensated for by the recidivism data obtained from the Federal Penitentiary Services. These data were obtained for 11 of the 13 inmates who could not be interviewed. Unfortunately, these data do not give us any information about inmates' post-release behavior other than their arrest records. As a result, we cannot determine if these inmates made any steps at all towards rehabilitation. This may conceal any "improvements" in the man's behavior and does not reveal factors which may have affected his behavior once he was released. These factors will be discussed later in this chapter.

While recidivism has traditionally been viewed as an important measure of the success of the program, it has been criticized for being arbitrary, imprecise, and biased (Keller and Carlson, 1977; Gendreau and Leipciger, 1978; Wilson, 1980; Gendreau and Ross, 1979). It is argued that recidivism does not provide a complete picture of the ex-inmate's experiences and the impact of the education program. The success of a program may be evident in different ways for different inmates. It may have succeeded in helping an inmate with interpersonal, familial, education or employment problems. Simply because an ex-inmate regresses once 
and commits an offence may not be an indication that the program has not helped him in some way or even that it won't have long-term effects on his behaviour. All of these faccors should be taken into consideration when the success of a program is being evaluated.

It has been pointed out in this thesis that there are numerous factors that can prevent a program from having an effect on the participants. While this study did not attempt to measure all of these factors, they are important and should be taken into consideration. The first barrier is the internal structure of the prison. Prisons today have multiple goals which are not always compatible. Because wardens are under pressure to maintain control over inmates, the goal of rehabilitation must take second place to the goal of custody. Typically, the goal of custody is best accomplished by the use of coercion, while the goal of rehabilitation is best accomplished when inmates comply as a result of internalizing and accepting the legitimacy of the goal of rehabilitation (Etzioni, 1975). Prisons attempt to achieve these two goals by having two types of staff, one which consists of treatment specialists and one composed of custody personnel. However, these two groups have distinct structures and often contradictory directives (Cressey, 1959). The result is a high degree of aissensus within the prison concerning general values, organization goals, and the means employed to attain them. 
The implications this has for rehabilitation are serious. The dissensus within the prison can effectively block inmates' perception of the rehabilitation goal. This prevents the internalization of this goal and consequently inmates' failure to voluntarily participate in their own rehabilitation (Cloward, 1960).

The inmate social system is also a barrier to rehabilitation. This system is antisocial and anti-administration. The values and norms which dominate this system define proper behavior for inmates in their relations with other inmates and staff (Sykes and Messinger, 1960). It was discussed in Chapter 3 that the behavior norms of the inmate social system conflict with the conduct norms directed to the inmate by the administration. The result is that inmates' adherence to the norms of the inmate social system must be at least weakened before a rehabilitation program can be effective. While this study did not find that participating in this program weakened inmates' endorsement of the inmate code, the results may be biased because of the nature of the indicators employed as measures of the variables. It seems that the traditional measures of "prisonization", or the degree of assimilation of the inmate social system, are not appropriate for participants of a rehabilitation program. The indicators of the conduct norms of the inmate community also tend to be indicators of behavior that is encouraged by the program staff. Inmates 
who participated in the program were forced to spend a lot of time with each other and to engage in discussion. Because of the high demands of the program it would probably be accurate to say that the participants remained in the program because they were receiving some sort of satisfaction from their involvement, regardless of whatever their original motives were for volunteering for the program. In effect, the program may have isolated a small group of inmates who shared common interests. As a result, the participants probably developed close relationships with each other and not necessarily with inmates who were not in the program. The indicators of prisonization, however, do not differentiate which inmates are being referred to in the responses to the items concerning inmate's reference group preference. Therefore, these indicators are probably not valid measures of prisonization for inmates who have participated in a program. This should be a consideration for future research in this area.

Other barriers to the success of the program exist once the inmate leaves prison. Chapter 4 discusses some of the difficulties an ex-inmate experiences when he attempts to re-enter society. Social relationships and employment, educational and financial problems are often great disappointments for an ex-inmate. While this study attempted to find out what types of problems inmates were faced with once they 
were released from prison and what effect the program had on minimizing these problems, it was not possible to obtain data on all inmates. However, the data which were collected indicate that inmates who were recidivists admitted to having more problems than those who were classified as successes. The data also suggest that the program increased the bonds inmates have with conventional society and decreased their criminal bonds. This may have had an impact on their recidivism rates. Two projects carried out in the U.S. also found that minimizing the difficulties an ex-inmate must confront can have an impact on recidivism and post-release adjustment (Seashore et al., 1976; Belenko and Friedman, 1977). Both of these studies suggest that combining an intensive educational program with extensive post-release services might have an impact on recidivism rates. The importance of this issue warrants further investigation in future research efforts.

This discussion concerning the barriers to rehabilitation programs and the possible bias involved with using only recidivism as a measure of the success of a project has been intended to explain the complexity involved with doing evaluation research in the area of corrections, and ultimately, the difficulty of drawing any definite conclusions concerning the success of a program. It is understandable that policy makers and prison administrators want to know "what works" or what "cures" criminal behavior. This is not a question that 
can be given a conclusive answer at this point. While the analysis of these data revealed few statistically significant. differences between the experimental and control group at B.C. Penitentiary, it can be argued that the findings also suggest that the program had an effect on inmates' social bonds and recidivism rates. Taking into consideration the short duration of the program, the methodological problems encountered, the long period of time between the conclusion of the program and the release of some inmates, as well as the lack of postrelease supports, the fact that the findings were positive is encouraging. Also encouraging is the fact that the inmates expressed much satisfaction with the project. They said they had enjoyed the program and felt they had benefitted from their participation. Some of the ways they said the program helped them included: improving their ability to communicate, broadening their outlook so they could see more than one side to an issue, and making them more accepting of others. Evidence of inmates' committment to the program is the fact that all but one of them kept their word and gave up opportunities to transfer to an institution of a reduced security level. The staff at B.C. Penitentiary and Matsqui Institution were also positive about the program. They felt the program had improved the attitude of many of the participants. Even though they judged many of the participants to be troublemakers, the number of disciplinary violations reported for 
these inmates was extremely low during the program. These findings support the contention that there is need for more well-designed and carried-out evaluations of prison education programs. Evidence for this also comes from an evaluation of the University of Victoria Program which was carried out at Matsqui and Kent Institutions in British Columbia (Ayers et al., 1980). This program attempted to incorporate some of the recommendations made by the researchers involved with the Donner Project. Ayers et al. (1980) report that the program had a significant effect on recidivism rates. Their findings also provided evidence that attitude change, cognitive development, improved employment opportunities and changed life goals all play a role in facilitating avoidance of trouble with the law.

Some differences between the University of Victoria Program and the Donner Program that were improvements in the design include a longer duration of the program, a shorter period of time between the conclusion of the program and the release of the inmates, and a larger sample size. First, the length of time inmates participate in the program can be crucial to the success of the program, especially when the extensive educational deficiencies of many of the inmates are taken into consideration. Secondly, the length of time between the completion of the program and release from prison should be minimized as much as possible. It is unlikely that 
any effects the program might have had would last for very long if the inmates had to remain in prison. Thirdly, a larger sample increases the reliability of the findings. It is difficult to have a lot of confidence in findings that are based on only a few cases.

In summary, the findings of the Donner Program and the University of Victoria Program are encouraging and support the contention that well designed and carried out prison education programs can be successful in rehabilitating offenders. Further research should be concerned with measuring the "success" of programs in a variety of ways, taking into consideration that rehabilitation may be evident for different inmates in different ways, and that it is a matter of degree as opposed to an either-or phenomenon. 
Table 1

Number of University Courses Completed by the Inmates

\begin{tabular}{lcc} 
& Matsqui & $\begin{array}{c}\text { British Columbia } \\
\text { Penitentiary }\end{array}$ \\
\cline { 2 - 3 } Four full courses & 1 & 1 \\
Three full courses & 4 & 1 \\
Two full courses & 5 & 12 \\
One full course & 1 & 2 \\
One half course & 1 & 1 \\
0 course & 1 & -17
\end{tabular}

* Two other inmates were originally assignea to the Matsqui experimental group. One of these inmates escaped and the other was paroled before completion of the program. 
Table 2

Number of Inmates By Type of Response to the Question: "What do you think the 'Donner' Program has done for you?"

\begin{tabular}{lccc} 
Classification of Responses & Matsqui & & $\begin{array}{c}\text { British Columbia } \\
\text { Penitentiary }\end{array}$ \\
\cline { 2 - 3 } $\begin{array}{l}\text { Style of Perceiving Problems } \\
\text { More Accepting of Society }\end{array}$ & 11 & 4 \\
$\begin{array}{l}\text { More Accepting of Self and } \\
\text { Others (less self-centered) }\end{array}$ & 4 & 3 \\
More Confident - Committed & 3 & 5 \\
Broadened Outlook & 6 & 5 \\
Educational Effects & 15 & 2 \\
Number of Inmates Interviewed & 16 & -11
\end{tabular}


Table 3

Responses to the Item: "Project Inmates Will

Be Less Likely To Violate Parole" (in percent)

B.C. P. B.C. P. Matsqui Matsqui

Experimental Control Experimental Control

Agree

93.8

45.5

75.0

16.7

Neutral

6.3

45.5

8.3

16.7

Disagree

0.0

$\mathrm{N}=15$

\section{1}

11
16.6

66.7

12 
Table 4

Analysis of Variance for Conformity to Staff Norms

Pre-test

B. C. Penitentiary Experimental Group

B. C. Penitentiary Control Group

Post-test

B. C. Penitentiary Experimental Group $\quad 16.57$

B. C. Penitentiary Control Group

15.70

$\underline{\bar{X}} \quad \underline{\text { F-Ratio }} \quad$ Significance Level

17.07

3.090

.0927

14.90
.4427 
Table 5

Conformity to Staff Norms (in percent)

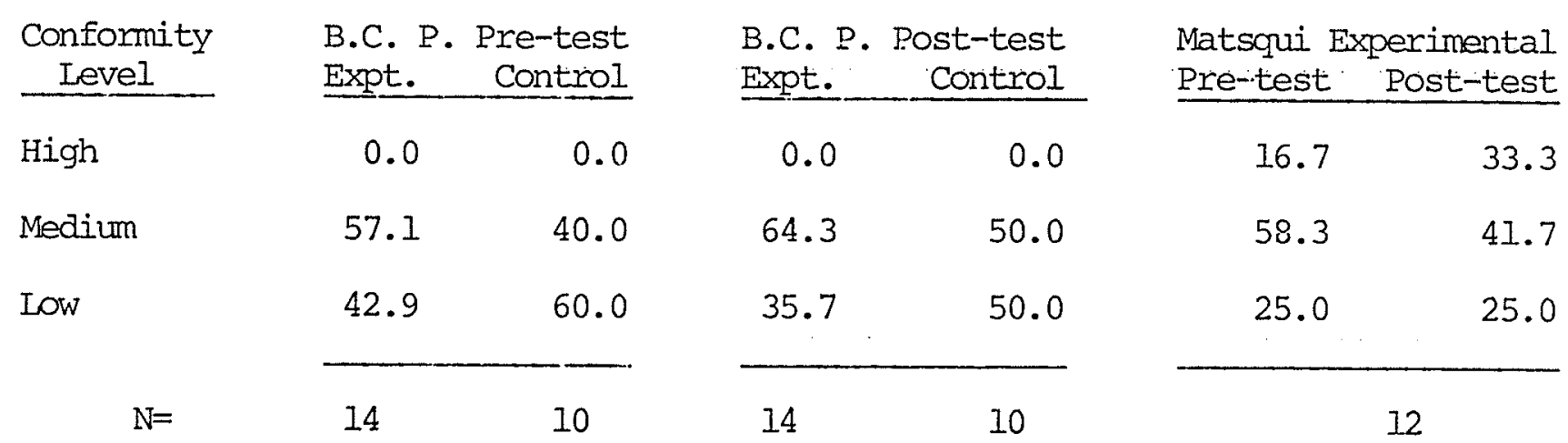


Table 6

Responses to the Item: "I Would Talk About Personal Matters:" (in percent).

B.C. P. Experiment Pre-test Post-test

To no inmate.

Only to my close friends in here.

Only to inmates

I know well.

To any inmate.

$N=$
46.7

33.3

33.3

53.5

13.3

20.0

0.0

0.0

15
B.C. P. Control Pre-test Post-test

30.0

30.0

40.0

40.0

30.0

30.0

0.0

0.0

$\overline{10}$

Matsqui Experiment Pre-test Post-test

8.3

25.0

58.3

41.7

25.0

25.0

8.3

8.3

12 
Table 7

Responses to the Item: "I Would Let Myself be Punished by Institutional Officials for Something I Didn't Do:" (in percent)

\begin{tabular}{|c|c|c|c|c|c|c|}
\hline & $\begin{array}{l}\text { B.C. P. } \\
\text { Pre-test }\end{array}$ & $\begin{array}{l}\text { periment } \\
\text { Post--test }\end{array}$ & $\begin{array}{l}\text { B.C. P. } \\
\text { Pre-test }\end{array}$ & $\begin{array}{l}\text { Control } \\
\text { Post-test }\end{array}$ & $\begin{array}{l}\text { Matsqui } \\
\text { Pre-test }\end{array}$ & $\begin{array}{c}\text { Experiment } \\
\text { Post-test }\end{array}$ \\
\hline Never. & 26.7 & 13.3 & 22.2 & 0.0 & 33.3 & 25.0 \\
\hline $\begin{array}{l}\text { Only to protect } \\
\text { a close frienc. }\end{array}$ & 20.0 & 20.0 & 11.1 & 22.2 & 8.3 & 16.7 \\
\hline $\begin{array}{l}\text { Only to protect } \\
\text { inmates that I } \\
\text { know well. }\end{array}$ & 13.3 & 13.3 & 0.0 & 0.0 & 25.0 & 16.7 \\
\hline $\begin{array}{l}\text { To protect any } \\
\text { inmate at all. }\end{array}$ & 40.0 & 53.3 & 66.7 & 77.8 & 33.3 & 41.7 \\
\hline$N=$ & & & & 9 & & 12 \\
\hline
\end{tabular}


Table 8

Responses to the Item:

"I Would Share My Food and Cigarettes:" (in percent)

With no one.

Only with my close friends.

Only with inmates that I know well.

With any inmate
B.C. P. Control

B.C. P. Experiment

Post-test

0.0

0.0

6.7

6.7

30.0

10.0

60.0

40.0

30.0

40.0

15
40.0

50.0

53.3

$\longrightarrow$

10
Matsqui Experiment Pre-test

Post-.-test

8.3

0.0

8.3

8.3

25.0

33.3

53.3

58.3

12 
Table 9

Responses to the Item: "When I'm Released I would be Willing to Invite Into my Home:" (in percent)

B.C. P. Experiment Pre-test Post-test

No one who has ever done time

Only those inmates who are my close friends

Only those inmates that I know well

Any inmate

50.0

35.7

7.1
B.C. P. Control Pre-test

Post-test

$7.1 \quad 14.3$

64.3

4.0 .0

30.0

41.7

25.0

14.3

50.0

40.0

10.0

30.0

7.1

14

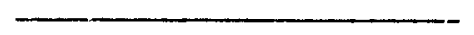

10
Matsqui Experiment Pre--test

Post-test

8.3

8.3

$\mathrm{N}=$

-

41.7

8.3 0.0 
Table 10

Responses to the Item: "Which of These

Tells Best How You Relate to Other Inmates: " in percent)

Pre-test Post-test

Stay by myself

Know many inmates

but not be friendly

with any of them

Try to make a few inmate friends.

Make as many

friends as I can
B.C. P. Experiment
13.3

13.3

60.0

53.3

13.3

0.0

15
B.C. P. Control

Pre-test Post-test

$13.3 \quad 0.0$

9.1

54.5

9.1

27.3

41.7

Matsqui Experiment Pre-test Post-test

33.3

50.0

36.4

33.3

45.5

9.1

8.3

0.0

\begin{tabular}{lr}
9.1 & 9.1 \\
\hline 11
\end{tabular}


Table 11

Responses to the Item:

"One Shouldn't Have Too Many Inmate Friends Here, Because Inmate Friends May Get You in Trouble or Take Advantage of You." (in percent)

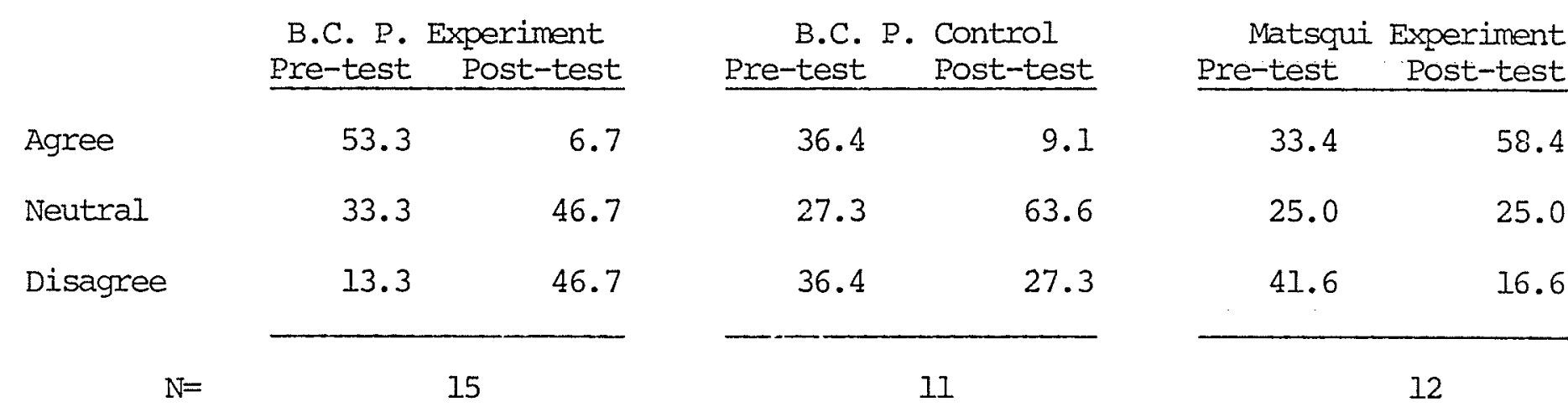


Table 12

Responses to the Item: "You Can't Stand it in Here Unless You Have Friends to Talk to." (in percent)

B.C. P. Experiment. Pre-test Post-test

\begin{tabular}{lrr} 
Agree & 60.0 & 53.4 \\
Neutral & 40.0 & 26.7 \\
Disagree & 0.0 & 20.0 \\
$\qquad \mathrm{~N}=$ & \multicolumn{1}{c}{15}
\end{tabular}

B.C. P. Control Pre-test Post-test

18.2 18.2

54.5

45.5

27.3

36.4

11
Matsqui Experiment

\begin{tabular}{rr} 
Pre-test & Post--test \\
\hline 50.0 & 58.3 \\
16.7 & 16.7 \\
33.3 & 25.0 \\
\hline
\end{tabular}

12 
Table 13

\section{Criminal Identification (in percent)}

\begin{tabular}{|c|c|c|c|c|c|c|}
\hline & \multicolumn{2}{|c|}{ B.C. P. Experiment } & \multicolumn{2}{|c|}{ B.C. P. Control } & \multicolumn{2}{|c|}{ Matsqui Experiment } \\
\hline & Pre-test & Post-test & Pre-test & Post..test & Pre-test & Post-test \\
\hline High & 13.3 & 0.0 & 9.1 & 36.4 & 8.3 & 0.0 \\
\hline Low & 86.7 & 100.0 & 90.0 & 63.6 & 91.7 & 100.0 \\
\hline $\mathrm{N}=$ & & 15 & & 11 & & 12 \\
\hline
\end{tabular}


Table 14

Analysis of Variance For Criminal Association Preference

$\overline{\mathrm{X}} \quad$ F-Ratio $\quad \begin{gathered}\text { Significance } \\ \text { Level }\end{gathered}$

Pre-test

B. C. Penitentiary Experimental Group

13.53

$1.918 \quad .1794$

B. C. Penitentiary Control Group

17.50

Post-test

B. C. Penitentiary Experimental Group $\quad 14.60$

$4.146 \quad .0534$

B. C. Penitentiary Control Group $\quad 19.70$ 
Table 15

Responses to the Item:

"A Person Like Myself Hasn't Much to Lose by comitting a Criminal offence." (in percent)

B.C. P. Experiment Pre-test Post-test

Agree

Disagree

$N=$ 7.1

14.3

78.6

92.9

14

7.1

0.0

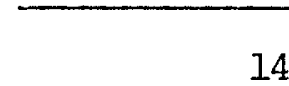

B.C. P. Control.

Pre-test

20.0

10.0

70.0
Post-..test

10.0

10.0

20.0

10
Matsqui Experiment Pre-test Post-test

\begin{tabular}{rr}
8.3 & 0.0 \\
0.0 & 0.0 \\
91.7 & 100.0 \\
\hline
\end{tabular}


Table 16

Responses to the Item:

"Money is the Only Reason to Have a Job." (in percent)

\begin{tabular}{|c|c|c|c|c|c|c|}
\hline & \multicolumn{2}{|c|}{ B.C. P. Experiment } & \multicolumn{2}{|c|}{ B.C. P. Control } & \multicolumn{2}{|c|}{ Matsqui Experiment } \\
\hline & Pre-test & Post-test & Pre-test & Post-test & Pre-test & Postrutest \\
\hline Agree & 21.3 & 7.1 & 30.0 & 30.0 & 16.7 & 16.7 \\
\hline Neutral & 14.3 & 28.6 & 20.0 & 20.0 & 8.3 & 0.0 \\
\hline Disagree & 64.3 & 64.3 & 50.0 & 50.0 & 75.0 & 83.3 \\
\hline$N=$ & & 14 & & 10 & & 12 \\
\hline
\end{tabular}


Table 17

Responses to the Item

"A Person Should Never Stop Trying to Get Ahead." (in percent)

\begin{tabular}{|c|c|c|c|c|c|c|}
\hline & B.C. P. & speriment & B.C. $P$ & Control & Matsqu & xperiment \\
\hline & Pre-test & Post--test & Pre..test & Post--test & Pre-test & Post-test \\
\hline Agree & 7.1 & 0.0 & 0.0 & 0.0 & 8.3 & 0.0 \\
\hline Neutral & 7.1 & 7.1 & 0.0 & 10.0 & 8.3 & 16.7 \\
\hline Disagree & 85.7 & 92.8 & 100.0 & 90.0 & 88.3 & 83.3 \\
\hline$N=$ & & 14 & & 10 & & 12 \\
\hline
\end{tabular}


Table 18

Responses to the Item:

"What Do You Think Are Your Chances of Being Returned to Prison at Some Time in the Future?" (in percent)

B.C. P. Experiment

Pre-test Post-test

1. Strong Chance

2. Moderate Chance

0.0

0.0

0.0

3. Small Chance

4. No Chance

$N=$

$\overline{\mathrm{X}}=$

78.6

64.3

14.3

21.4

14

2.9
3.2
B.C. P. Control

Pre-test Post-test

$0.0 \quad 10.0$

20.0
10.0

40.0

40.0

10

2.9
Matsqui Experiment Pre-test Post-test

$8.3 \quad 0.0$

$33.3 \quad 25.0$

$41.7 \quad 41.7$

$16.7 \quad 33.3$

12

2.7

3.1 
Responses to the Item:

"Do You Think That Members of Your Family Will Do What They Can to Help You When You Get Out?" (in percent)

1. All of them

2. Most of them

3. Some of them

4. None of them

$\mathrm{N}=$

$\overline{\mathrm{X}}=$
B.C. P. Experiment Pre-test Post-test

\begin{tabular}{rr}
40.0 & 33.3 \\
40.0 & 46.7 \\
13.3 & 20.0 \\
6.7 & 0.0 \\
\hline
\end{tabular}

15

\begin{tabular}{rr}
$\begin{array}{rr}\text { B.C. P. Control } \\
\text { Pre-test }\end{array}$ & Post-itest \\
\hline 44.5 & 44.5 \\
22.2 & 11.1 \\
11.1 & 11.1 \\
22.2 & 33.3 \\
\hline
\end{tabular}

$9 *$
Matsqui Experiment Pre-test

Post-test

$41.7 \quad 58.3$

25.0

8.3

33.3

33.3

$0.0 \quad 0.0$

12

$2.1 \quad 2.3$

$\begin{array}{lll} & & \\ & 12 & \\ 1.9 & & 1.7\end{array}$

*Two inmates in this group responded that they did not have a family. They were excluded from the analysis of this item. 
Responses to the Item:

"Do You Think That Relationships With Your Family Will be Better After Your Release Than

Before You Came to Prison." (in percent)

B.C. P. Experiment

Pre-test Post-test

1. Much Better

2. Somewhat Better

3. A Little Better

4. A Little Worse

5. Somewhat worse

6. Much Worse

$N=$

$\overline{\mathrm{X}}=$
35.7

14.3

21.4

21.4

7.1

0.0

14
0.0

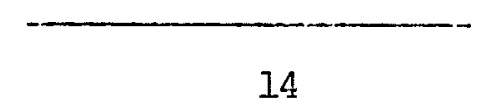

2.5
B.C. P. Control Pre-test Post-test

14.3

14.3

28.6

14.3

28.6
2.3
0.0

0.0

28.6

0.0

28.6

28.6

14.3

7

3.3

4.0
Matsqui Experiment Pre-test Post-test
63.6
63.6

0.0

9.1

18.2

18.2

$9.1 \quad 9.1$

0.0

0.0

9. 1

0.0

11

2.1

1.7 
Table 21

Responses to the Item:

"Do You Think That Your Old Friends. Will Want to Go Around With You After You Get Out?" (in percent).

B.C. P. Experiment B.C. P. Control

Pre-test

Pre-test Post-test

1. All of them

$$
23.1
$$

7.7

27.3

27.3

2. Most of them

30.8

38.5

27.3

27.3

3. Some of them

46.2

53.8

45.5

45.5

4. None of them

$\overline{\mathrm{X}}=$

\begin{tabular}{|c|c|}
\hline 0.0 & 0.0 \\
\hline \multicolumn{2}{|c|}{13} \\
\hline 2.2 & 2.5 \\
\hline
\end{tabular}

0.0

0.0

17

Matsqui Experiment Pre-test

Post-test

10.0

20.0

30.0

20.0

50.0

60.0

10.0

0.0

$\begin{array}{lll} & 17 & \\ 2.2 & & 2.2\end{array}$

10

2.6

2.4 
Table 22a

B.C. Penitentiary Innates: Help Expected From Deviant Versus Conventional Friends After Release (in percent)

B.C. P. Experiment Pre-test Post-test Deviant Convent. Deviant Convent. Friends Friends Friends Friends

All of them

Most of them

Some of them

None of them

\begin{tabular}{rrrr}
100.0 & 11.1 & 0.0 & 0.0 \\
0.0 & 33.3 & 100.0 & 37.5 \\
0.0 & 55.6 & 0.0 & 62.5 \\
0.0 & 0.0 & 0.0 & 0.0 \\
\hline \multicolumn{5}{c}{$\mathrm{N}=10$}
\end{tabular}

B.C. P. Control Pre-test Deviant Convent. . Deviant Convent. Friends Friends Friends Friends

\begin{tabular}{rrrr}
50.0 & 40.0 & 100.0 & 33.3 \\
50.0 & 20.0 & 0.0 & 33.3 \\
0.0 & 40.0 & 0.0 & 33.3 \\
0.0 & 0.0 & 0.0 & 0.0 \\
\hline \multirow{5}{*}{$\mathrm{N}=7$}
\end{tabular}


Table $22 \mathrm{~b}$

Matsqui Inmates: Help Expected From Deviant Versus Conventional Friends After Release (in percent)

Matsqui Experiment

\begin{tabular}{rrrr}
\multicolumn{2}{c}{ Pre-test } & \multicolumn{2}{c}{ Post-test } \\
$\begin{array}{r}\text { Deviant } \\
\text { Friends }\end{array}$ & $\begin{array}{c}\text { Convent. } \\
\text { Friends }\end{array}$ & $\begin{array}{l}\text { Deviant } \\
\text { Friends }\end{array}$ & $\begin{array}{l}\text { Convent. } \\
\text { Friends }\end{array}$ \\
\hline 0.0 & 0.0 & 25.0 & 0.0 \\
50.0 & 33.3 & 25.0 & 33.3 \\
50.0 & 33.3 & 50.0 & 66.7 \\
0.0 & 33.3 & 0.0 & 0.0 \\
\hline
\end{tabular}

$N=7$ 
Responses to the Item:

"Do You Think That Relationships With People You Work For Will

Be Better After Your Release Than Before You Came to Prison?" (in percent)

B.C. P. Experiment

Pre-test Post-test

1. Much better

2. Somewhat better

3. A Little better

4. A little worse

5. Somewhat worse

6. Much worse
14.3

14.3

21.4

21.4

28.6

0.0

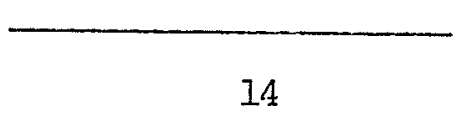

3.4

0.0

\begin{abstract}
2.4
\end{abstract}
B.C. P. Control

Pre-test Post-test

14.3

28.6

28.6

28.6

0.0

0.0

$\overline{\mathrm{X}}=$

\begin{tabular}{rr}
$\begin{array}{c}\text { Matsqui Experinent } \\
\text { Pre-test }\end{array}$ & Post-test \\
\hline 18.2 & 51.5 \\
27.3 & 0.0 \\
45.5 & 36.4 \\
9.1 & 9.1 \\
0.0 & 0.0 \\
0.0 & 0.0 \\
\hline
\end{tabular}

11

2.42 .0


Table 24

Responses to the Item:

"Nothing in Life is Worth the Sacrifice of Iosing Contact With My Family." (in percent).

\begin{tabular}{|c|c|c|}
\hline & $\begin{array}{l}\text { B.C. P. } \\
\text { Pre-test }\end{array}$ & $\begin{array}{l}\text { periment } \\
\text { Post-test }\end{array}$ \\
\hline Agree & 73.3 & 73.3 \\
\hline Neutral & 6.7 & 6.7 \\
\hline Disagree & 20.0 & 20.0 \\
\hline
\end{tabular}

$\mathrm{N}=$
B.C. P. Control

Pre-test

50.0

20.0

30.0

.6 .0

10
Matsqui Experiment Pre-test Dost-test

33.3

50.0

33.3

25.0

33.4

25.0 
Table 25

Responses to the Item

"My Family Has Confidence in Me." (in percent)

B.C. P. Experiment Pre-test Post-test

$\begin{array}{lrr}\text { Agree } & 57.1 & 71.4 \\ \text { Neutral } & 28.6 & 21.4 \\ \text { Disagree } & 14.2 & 7.1 \\ \mathrm{~N}= & & 14\end{array}$

B.C. P. Control Pre-test Dost-test

40.0

30.0

30.0

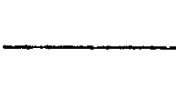

Matsqui Experiment

\begin{tabular}{rr} 
Pre-test & Post-test \\
\hline 58.3 & 49.9 \\
8.3 & 16.7 \\
33.3 & $\ldots$ \\
\hline
\end{tabular}


Table 26

Analysis of Variance for

Orientation to Criminal Means

Pre-test

B. C. Penitentiary Experimental Group

26.2

.002

.9657

B. C. Penitentiary Control Group

26.1

Post-test

B. C. Penitentiary Experimental Group

23.8

B. C. Penitentiary Control Group

24.9

Significance Level

$\underline{\text { F-Ratio }}$

cheve


Table 27

Post--Release Success of Project Inmates (in percent)

B.C. P. B.C. P. Matsqui Matsqui Experimental Control Experimental Control

Clear

Reformation

Marginal

Reformation

Marginal

Failure

Clear

Recidivists

$\mathrm{N}=$
35.3

(6)

0.0

5.9

(1)

58.8

(10)

21.4

(3)

0.0

14.3

(2)

64.3

(9)

-

17

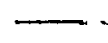

14
30.8

(4)

0.0

7.7

(I)

61.5

(8)
25.0

(3)

0.0

0.0

75.0

(9)

12 
Table 28

Gammas for Recidivism and Possible Intervening Variables

I. PRISONIZATION MEASURES

Garmas

1. Conformity to Staff Norms

2. Expressed Solidarity

(i) "I would talk about personal matters:"

(ii) "I would let myself be punished by institutional officials for something I didn't do:"

$-15836$

(iii) "I would share my food and cigarettes:" $-38851 \mathrm{~A}$

(iv) "When I'm released I would be willing to invite into my home:"

3. Isolation vs. Friendship Orientation

(i) "Which of these tells best how you relate to other inmates?"

$-.18965 \mathrm{~A}$

(ii) "One shouldn't have too many friends here because inmate friends may get you in trouble or take advantage of you."

(iii) "You can't stand it in here unless you have friends to talk to."

II. SOCIAL BONDS

1. Reference Group Orientation

(i) Criminal Identification

(ii) Criminal Association Preference

$-.37809$

2. Stake in Conformity

(i) "A person like myself hasn't much to lose by committing a criminal offence." 
Table 28 (Continued)

2. (Continued)

(ii) "Money is the only reason to have a job." $.12000 \mathrm{~A}$

(iii) "A person should hever stop trying to get ahead."

(iv) "What do you think are your chances of being retumed to prison at some time in the Euture?"

3. Contact With Others Outside of the Institution

(i) "During the past month, have you received any letters or post cards from relatives or friends outside the institution?"

(ii) "During the past month have you written any letters or post cards to relatives or friends outside the institution?"

(iii) "During the past month, have you had any visits from relatives or friends outside the institution?"

4. Post Prison Expectations

(i) "Do you think that members of your family will do what they can to help you when you get out?"

(ii) "Do you think that your old friends will want to go around with you when you get out?" -..11309

(iii) "Do you think that relationships with your family will be better after your release than before you came to prison?"

(iv) "Do you think that relationships with people you work for will be better after your release than before you came to prison? 
Table 28 (Continued)

5. Bonds With Family Members

(i) "Nothing in life is worth the sacrifice of losing contact with my family."

$-.23611 \mathrm{~A}$

(ii) "My family has confidence in me."

$.34928 A^{* *}$

(iii) "How well do you get along with your wife?" -.30612 A

6. Orientation to Criminal Means

$.02978 * *$

III.BIOGRAPHICAL INFORMATION

1. Age

$-.27505$

2. Length of Present Sentence

$\cdots .15170 \mathrm{~A}$

3. Length of Time Served

$-. .15571$

4. Alcoholism

$.44898 \mathrm{~A}$

5. Drug Use

$-.30077 * *$

6. Type of Offence Conmitted

Lambda $=.17647$

7. Period of Employment After Release

$-.52000 \mathrm{~A}^{\star *}$

8. Type of Job Obtained After Release

$.10526 \mathrm{~A}$

\section{ORIENTATION TO REHABILITATION}

The importance of each of the following institutional goals:

(i) "To change the feelings or attitudes of the inmates so they can understand themselves better."

$$
\begin{aligned}
& .05618 \mathrm{~A}^{* *} \\
& -.22034 * * \\
& -.42384 \mathrm{~A}^{* *}
\end{aligned}
$$$$
\begin{aligned}
& \text { "To punish men who have violated the } \\
& \text { law so they will not do it again." }
\end{aligned}
$$ 
Table 28 (Continued)

IV. (Continued)

(iv) "To protect the outside community."

$-.08633 A^{* *}$

(v) "io train men through education or work so that they will learn things they can use after their release."

$-.14498$

A Relationship is potentially artifactual

** Relationship is in the predicted direction 


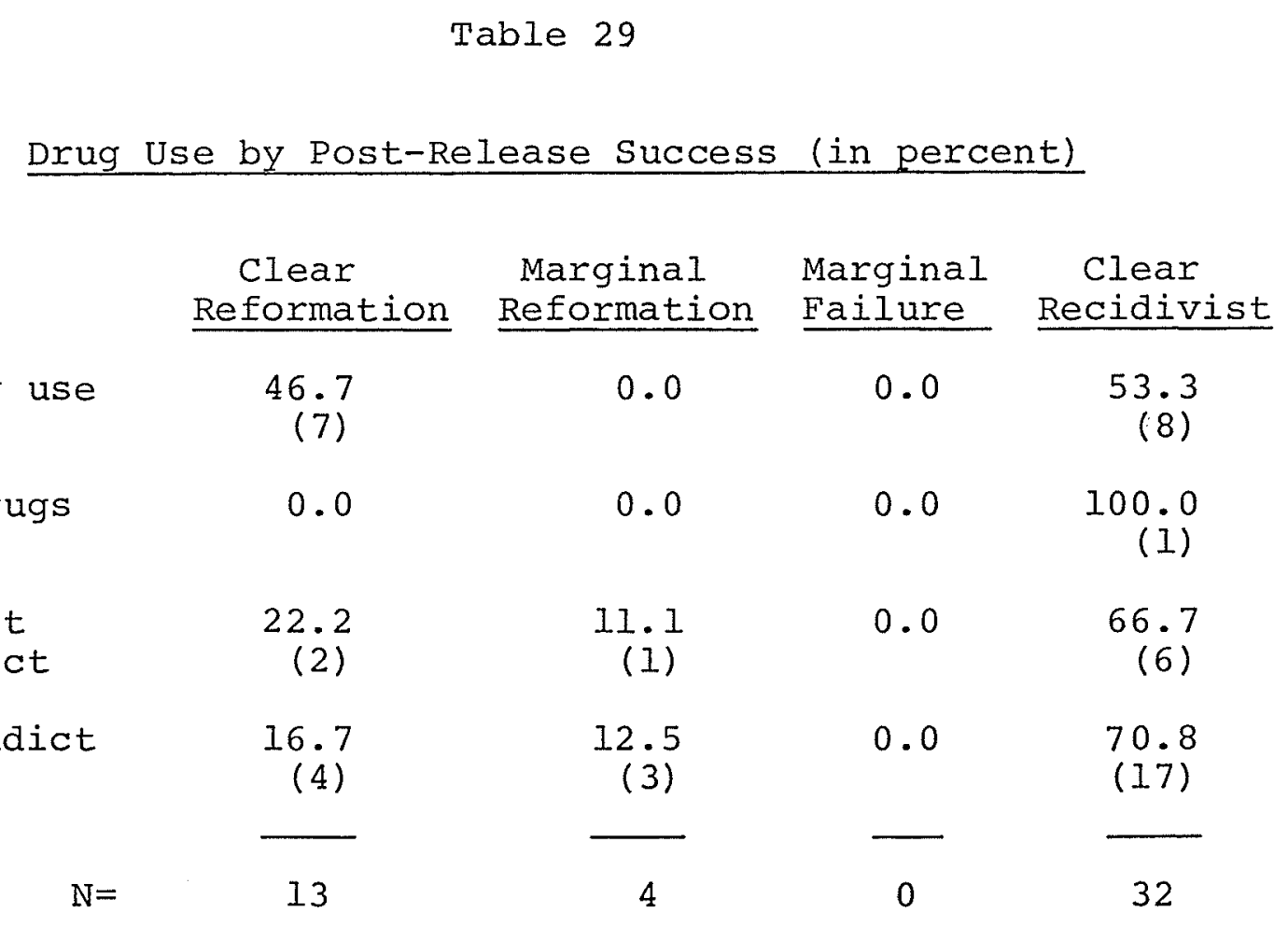


Table 30

\section{Alcohol Use by Post-Release Success (in percent)}

\begin{tabular}{|c|c|c|c|}
\hline $\begin{array}{c}\text { Clear } \\
\text { Reformation } \\
\end{array}$ & $\begin{array}{l}\text { Marginal } \\
\text { Reformation } \\
\end{array}$ & $\begin{array}{l}\text { Marginal } \\
\text { Failure } \\
\end{array}$ & $\begin{array}{c}\text { Clear } \\
\text { Recidivist } \\
\end{array}$ \\
\hline $\begin{array}{r}11.5 \\
(3)\end{array}$ & $\begin{array}{r}11.5 \\
(3)\end{array}$ & 0.0 & $\begin{array}{l}77.0 \\
(20)\end{array}$ \\
\hline $\begin{array}{r}66.7 \\
(2)\end{array}$ & 0.0 & 0.0 & $\begin{array}{r}33.3 \\
(I)\end{array}$ \\
\hline $\begin{array}{r}40.0 \\
(4)\end{array}$ & 0.0 & 0.0 & $\begin{array}{r}60.0 \\
(6)\end{array}$ \\
\hline 9 & 3 & 0 & 27 \\
\hline
\end{tabular}


Table 31

Drug Use* by Post-Release Success
Controliting for Alcoholism (in percent)

\begin{tabular}{|c|c|c|c|}
\hline $\begin{array}{l}\text { Clear } \\
\text { Reformation }\end{array}$ & $\begin{array}{l}\text { Marginal } \\
\text { Reformation }\end{array}$ & $\mathrm{Ma}$ & $\operatorname{Re}$ \\
\hline
\end{tabular}

No drug use

$$
25.0
$$

0.0

0.0

75.0

Soft drugs

40.0

(2)

0.0

0.0

(6)

User, not addict

0.0

50.0

(I)

0.0

14.2

(2)

0.0

(I)

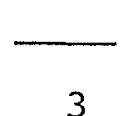

5

3

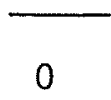

60.0

(3)

50.0

(I)

78.7

(11)

21

*These findings pertain to non-alcoholics only 
Table 32

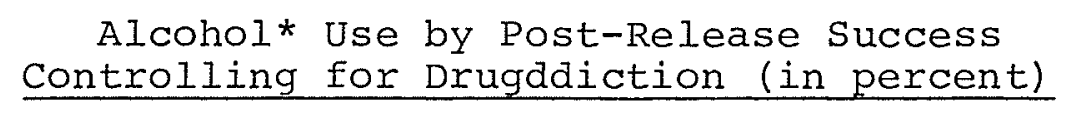

Clear Marginal Marginal Clear Reformation Reformation Failure Recidivist

No

Alcoholism

Some

Alcoholism

Alcoholic
7.8

(2)

100.0

(2)

57.1

(4)

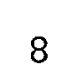

15.3

(I)

0.0

0.0

0.0

0.0

76.9

(10)

0.0

0.0

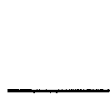

1
42.9

(3)

13

*These findings pertain to non-drug addicts only. 
161

Table 33

Period of Employment After Release

by Post-Release Success (in percent)

\begin{tabular}{|c|c|c|c|}
\hline $\begin{array}{l}\text { Clear } \\
\text { Reformation }\end{array}$ & $\begin{array}{l}\text { Marginal } \\
\text { Reformation }\end{array}$ & $\begin{array}{l}\text { Marginal } \\
\text { Failure }\end{array}$ & vist \\
\hline & & Failur & vist \\
\hline
\end{tabular}

Employed 25 percent of 10.0

10.0

0.0

80.0

time or less

Employed 50

percent of

25.0

25.0

0.0

50.0

time

Employed 75

percent of

38.7

3.2

0.0

58.1

time or more

$\mathrm{N}=$

14

0

28 
Table 34

Perception of the Importance of Correctional Goals by Group (in percent)

\begin{tabular}{|c|c|c|c|c|c|c|c|}
\hline & & B.C. P. & periment & B.C. I & Control & Matsqui & Experiment \\
\hline & & Pre-test & Post-test & Pre-test & Post-test & Pre-test & Post-test \\
\hline 1. & Change Attitudes & 31.3 & 81.3 & 40.0 & 60.0 & 66.7 & 75.0 \\
\hline 2. & Punishment & 50.0 & 50.0 & 20.0 & 50.0 & 45.5 & 54.6 \\
\hline 3. & $\begin{array}{l}\text { Training in } \\
\text { Discipline }\end{array}$ & 50.1 & 50.0 & 30.0 & 40.0 & 36.4 & 54.6 \\
\hline - & $\begin{array}{l}\text { Protect } \\
\text { Community }\end{array}$ & 50.1 & 68.8 & 50.0 & 80.0 & 58.3 & 83.3 \\
\hline 3 & $\begin{array}{l}\text { Training through } \\
\text { Education }\end{array}$ & 43.8 & 75.0 & 45.5 & 54.6 & 58.3 & 50.0 \\
\hline & & & 16 & & 10 & & 12 \\
\hline
\end{tabular}


Table 35

Perception of the Importance of Correctional Goals by Post-Release Success (in percent)

1. Change Attitudes

\begin{tabular}{|c|c|c|c|}
\hline \multicolumn{4}{|c|}{ PRE--TEST } \\
\hline Clear & Marginal & Marginal & Clear \\
\hline Reform & Reform & Fail & Fail \\
\hline 53.8 & 0.0 & 25.0 & 47.8 \\
\hline 30.8 & 0.0 & 50.0 & 39.1 \\
\hline 7.7 & 0.0 & 50.0 & 56.5 \\
\hline 46.2 & 0.0 & 50.0 & 56.5 \\
\hline 53.8 & 0.0 & 25.0 & 60.9 \\
\hline 13 & 0 & 4 & 23 \\
\hline
\end{tabular}

\begin{tabular}{|c|c|c|c|}
\hline \multicolumn{4}{|c|}{ POST-MEST } \\
\hline Clear & Marginal & Marginal & Clear \\
\hline Reform & Reform & Fail & Fail \\
\hline 84.6 & 0.0 & 75.0 & 69.6 \\
\hline 23.1 & 0.0 & 50.0 & 65.2 \\
\hline 30.8 & 0.0 & 75.0 & 52.2 \\
\hline 61.5 & 0.0 & 75.0 & 78.3 \\
\hline 76.9 & 0.0 & 50.0 & 56.5 \\
\hline 13 & 0 & 4 & 23 \\
\hline
\end{tabular}


Table 36

Problems Encountered by Inmates on Release From Prison by Post-Release Success (in percent)

No problems

Interpersonal problems

Personal and Emotional Adjustment

Lack of Employment (Financial)

Alcohol and Drugs

Stigma attached to being an ex-convict
Marginal

Recidivist

(0)

33.3

(1)

33.3

(I)

(8)

50.0

(6)

(0)

33.3

(I)

(3)

8.3

(1)

66.7

(2)

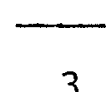

Clear Recidivist

12.0

(3)

56.0

(14)

72.0

(18)

36.0

(9)

36.0

(9)

28.0

(7) 
Table 37

Iong Term Plans by Post-Release Success (in percent)

\begin{tabular}{ccc}
$\begin{array}{c}\text { Clear } \\
\text { Reformation }\end{array}$ & $\begin{array}{c}\text { Marginal } \\
\text { Recidivist }\end{array}$ & $\begin{array}{c}\text { Clear } \\
\text { Recidivist }\end{array}$ \\
\cline { 2 - 3 }$(9)$ & $(0)$ & $\begin{array}{c}90.1 \\
(19)\end{array}$ \\
40.0 & 50.0 & 52.4 \\
$(4)$ & $(1)$ & $(11)$ \\
20.0 & 50.0 & 23.8 \\
$(2)$ & $(1)$ & $(11)$ \\
$(0)$ & & 9.5 \\
10.0 & $(0)$ & $(2)$ \\
$(1)$ & 50.0 & 14.3 \\
10 & $(1)$ & $(3)$ \\
\hline
\end{tabular}




\section{BIBITOGRAPHY}

Adams, stuart

1974

Adams, Stuart 1976
"Evaluations Research in Corrections: Stakes and Prospects Revisited". Federal Probation March.

"Evaluation: A Way Out of Rhetoric." Pp. 75-91 in R. Martinson, T. Palmer and S. Adams, Rehabilitation, Recidivism and Research. Hackensack, N.J.: National Council on Crime and Delinquency.

Akers, Ronald R., Norman S. Hayner and Werner Gruninger 1977

"Prisonization in Five Countries : Type of Prison and Inmate Characteristics." Criminology 14 no.4: $527-554$.

Amos, William E. 1974

"The Philosphy of Corrections: Revisited." Federal Probation 38:43-46.

Atchley, Robert C. and M. Patrick McCabe 1968 "Socialization in Correctional Commmities:

A Replication" American Sociological Review 33: $774-785$.

Austin, Roy I. 1977

"Social Iearning and Social Control: A Comment on Conger" Criminology 15, 1, Pp. 111-116.

Ayers, J. Douglas 1979

"A Model for Prison Education Programs and Guidelines for their Operation." Journal of Correctional Education 30:3-7.

Ayers, Douglas, Stephen Duquid, Catherine Montaque and Sonia Wolowidnyk 1980 Effects of University of Victoria Program: A Post Release Study Report prepared for the Ministry of the Solicitor General of Canada May 1 .

Bailey, Walter C. 1966

"Correctional Outcome: An Evaluation of 100 Reports." The Journal of Criminal Law, Criminology and Police Science 57:153-160. 
Belenko, Steven R. and Lucy N. Friecman 1977

"The Impact of Supported Work on Arrest Rates of Ex-Addicts." Federal Probation 41 (June) :14-20.

Bernstein, Ilene Nagel

1975 "Evaluations Research in Corrections: Status and Prospects Revisited." Federal Probation 14 (March): 56-57.

Brodsky, Stanley L. 1975

Families and Friends of Men in Prison Lexington, Mass.: D. C. Heath \& Co.

Cain, Richard E. 1979

"An Educational Approach to Rehabilitation." Journal of Correctional Education 30:10-12.

California Department of Corrections 1963 Research Division Annual Research Review, 1962. (Processed) Cited in David Greenberg Corrections and Punishment. Beverly Hills: Sage, 1977.

Chalfont, Caroline

1972

The Iorton Prison College Project: Third Year Final Report. Washington, D.C.: D.C. Department of Corrections.

Chaneles, Sol 1976

"Prisoners Can Be Rehabilitated - Now." Psychology Today (October) :129-133.

Chappell, Aldus Devon

1977 "The Family Home Evening Program at the Utah State Prison: Its History and Relationship to Recidivism" Unpublished Ph.D. Dissertation, Brigham Young University.

Clemmer, Donald 1958

The Prison Commity. New York: Holt Rinehart and Winston.

Cobean, Susan C. and Paul W. Power 1978

"The Role of the Family in the Rehabilitation of the Offender" International Journal of Offender Therapy and Comparative Criminology. 22:29-38. 
Cochran, A. W. 1965

"Is Education of Value to the Parolee?" Journal of Correctional Education 17 (July):22-24.

Cohen, Harold I. and James Filipczak 1971

A New Learning Environment. San Francisco: JosseyBass.

Conger, Rand D. 1976

"Social Control and Social Learning Models of Delinquent Behavior: A Synthesis" Criminology 14, Pp. 17-40.

Conger, Rand D. 1977

"Rejoinder" Criminology 15, 1, Pp. 117-126.

Cortright, Richard $W$.

1971 "Focus on the Future: Futurology for Correctional Education." Joumal of Correctional Education 23

(February) : 9-30.

Cressey, D. R.

1954

"Contridictory Theories in Correctional Group Therapy Programs." Federal Probation 17 (June) :20-21.

Cressey, D. R. 1959

"Contridictory Directives in Complex Organizations: The Case of the Prison" Administrative Science quarterly 4 (June) : I-19.

Caspo, Marg and Bernie Agg 1976

"Educational Rehabilitation of Delinquents in a Community Setting." Canadian Journal of Criminology and Corrections 12 (January):42-48.

Curry, William J. 1974

"Academic and Motivational Characteristics of Prison Inmates Enrolled in the Comminity College Program at North Carolina's Correctional Institution: An Exploratory Study". Unpublished Doctoral Dissertation, Northern Illinois University.

Dickover, R. M., V. E. Maynard and J. E. Painter 1971

"A Study of Vocational Training in the Califormia Department of Corrections Research Division." (Processed) Cited in David Greenberg Corrections and Punishment. Beverly Hills: Sage, $197 \overline{7}$ 
Eckenrode, Charles J.

1973 "Education's Contributions to Institutional Treatment Modules." Pp. 77-84 in Albert R. Roberts (ed.), Readings in Prison Education. Springfield: Charles C. Thomas.

Empey, LaMar and Steven G. Lubeck The Silverlake Experiment: Testing Delinquency Theory and Comunity Intervention. Chicago: Aldine Publishing Co.

Etizioni, Amitai

1975 A Comparative Analysis of Complex Organizations New York: The Free Press.

Fishman, Robert 1977

Criminal Recidivism in New York City: An Evaluation of the Impact of Rehabilitation and Diversion Services. New York: Praeger.

Fishman, Susan Hoffman and Albert S. Alissi 1979

"Strengthening Families as Natural Support System for offenders". Federal Probation V.43 no.3:16-2I.

Frank, Benjamin 1979

"The American Prison: The End of an Fra." Federal Probation 43 (September) :3-9.

Garabedian, $P$. 1963

"Social Roles and Processes of Socialization in the Prison Commity". Social Problems 11:139-152.

Gearhart, J. Walter, Harold I. Keith, and Gloria Clemmons 1967

"An Analysis of the Vocational Training Program in the Washington State Adult Correctional Institutions." State of Washington, Department of Institutions (Processed) Cited in Douglas Iipton, Robert Martinson, and Judith Wilks The Effectiveness of Correctional Treatment. New York: Praeger, 1975.

Gendreau, Paul and Mary Leipciger 1978

"The Development of a Recidivism Measure and Its Application in Ontario." Canadian Journal of Criminology 20 (January) :3-17.

Gendreau, Paul and Bob Ross 1979

"Effective Correctional Treatment: Bibliotherapy for Cynics." Crime and Delinquency 25 (October): $463-489$. 


\begin{abstract}
Glaser, Daniel
1969

The Effectiveness of a Prison and Parole System, Abridged Edition. Indianapolis: Bobbs-Merrill.

Glaser, Daniel 1978

Crime in our Changing Society. New York: Holt, Rinehart and Winston.

Glaser, Daniel 1979

"A Review of Crime-Causation Theory and Its Application." Pp. 203-238 in N. Morris and M. Tonry (eds.) Crime and Justice: An Annual Review of Research. V.I Chicago: The University of Chicago Press, 1979.
\end{abstract}

Gold, Martin 1978

"Scholastic Experiences, Self-esteem, and Delinquent Behavior: A Theory for Alternative Schools." Crime and Deliniquency (July) :290-308.

Greenberg, David 1977
"The Correctional Effects of Corrections: A Survey of Evaluations." Pp. 11l-148 in David Greenberg (ed.) Corrections and Punishment. Beverly Hills: Sage.

Griffin, Douglas K.

Ontario Institute for Studies in Education Review of Penitentiary Education and Training 1978-79. Phase I: Report to Reviewers. Ottawa: Canadian Penitentiary Service, 1978.

Griffin, Douglas K.

1978 "Can Education Reform Canada's Criminals?" Education Canada 18 (Summer) :22-25.

Grusky, 0 . 1959

"Organizational Goals and the Behavior of Informal Leaders". American Joumal of Sociology 65:59-67.

Hackler, James C. 1967

"Evaluation of Deinquency Prevention Programs: Ideals and Compromises." Federal Probation 31:22-26.

Hackler, James C. 1978

The Prevention of Youthful Crime: The Great Stumble Forward. Toronto: Methuen.

Halleck, Seymour L. and Ann D. Witte 1977 "Is Rehabilitation Dead?" Crime and Delinquency (October) : 372-332. 
Helfrich, John E. 1973

"One Effort to Upgrade Literacy in the Correctional Population." The Prison Journal 53:46-54.

Hepburn, John R. 1977

"Testing Alternative Models of Delinquency Causation." The Journal of Criminal Law and Criminology 67 no.4: $450-460$.

Hirschi, Travis 1969

Causes of Delinquency. Berkeley: University of California Press.

Holt, Norman and Donald Miller 1972

"Explorations in Inmate - Family Relationships". Research Report no. 46. Research Division, California Department of Corrections.

Homer, Eva Lee 1979
"Inmate-Family Ties: Desirable But Difficult." Federal Probation 43 (March) : 47-86.

Hoppe, Ronald A. 1973

"Attitude Change in the Penitentiary Through Education." Paper presented at the correctional Education Conference. Vancouver: University of Victoria (Mimeo).

Irwin, John 1970 The Felon. New Jersey: Prentice-Hall

Jacobson, Frank and Eugene MoGee 1965

"Englewood Project: Re-education: A Radical Correctional of Incarcerated Delinquents." Englewood, (Mimeographed). Cited in Douglas Lipton, Robert Martinson, and Judith Wilks The Effectiveness of Correctional Treatment. New York: Praeger, 1975.

Jeffery, C. Ray 1971

Crime Prevention Through Environmental Design. Beverly Hills: Sage Publications.

Jenkins, W. O., A. D. Witherspoon, M. D. Devine, E. K. DeValera, J. B. Muller, M. C. Barton, and J. M. MaKee 1974 "The Post-prison Analysis of Criminal Behavior and Iongitudinal Follow-up Evaluations of Institutional Treatment." (Processed) Cited in David Greenberg Corrections and Punishment. Beverly Hills: Sage, 1977. 
Joselson, $\mathrm{M}$.

1971

"Prison Education: A Major Reason for Its Impotence." Corrective Psychiatry 17:48-56.

Kaslow, Florence W. 1978

"Marital or Family Therapy for Prisoners and Their Spouses or Families." Prison Jourmal 58 no. 1:53-59.

Kassebaum, Gene, David A. Ward, and Daniel M. Wilner

1971

Prison Treatment and Parole Survival. New York:

Kellar, Sandra L. and Kenneth A. Carlson

1977

"Development of An Index to Evaluate Programs in a Correctional Setting." Canadian Journal of Criminology

Kerle, Ken

1973

"Penal Education: United States and Europe." The Prison Journal 53:4-25.

Ketterling, $M$. 1972

"Rehabilitation of Women in the Milwaukee County Jail: An Exploration Experiment." (Processed) Cited in David Greenberg Corrections and Punishment. Beverly
Hills: Sage, 1977 .

Kovacs, Frank W. 1967

"Evaluation and Final Report of the New Start Demonstration Project." Colorado Department of Employment (Processed). Cited in Douglas Lipton, Robert Martinson and Judith Wilks The Effectiveness of Correctional Treatment. New York: Praeger, 1975.

Laird, C. Alton 1971

A Study of the College Ievel Educational Program of the Texas Department of Corrections. (Processed). Cited in John J. March "Higher Education in American Prisons." in Crime and Delinguency Literature (March):

Ieger, Robert C. 1978

"Socialization Patterns and Social Roles: A Replication." The Journal of Criminal Law and Criminology 69 no. 4:627-634.

Leiberg, Ieon 1973

"Project Challenge" Pp. 155-171 in Albert R. Roberts (ed.), Readings in Prison Education. Springfield: 
Iewis, Morgan V., David C. Bumpper, Joan L. Meyer, Andrew Broughton, and Alice Beamesderfer

1973 Prison Education and Rehabilitation: Illusion or Reality?: A Case Study of an Experimental Program. Pennsylvania: Institute for Research on Human Resources.

Lewis, Morgan V. 1973

"The Humanities in Prison". The Prison Joumal V.53: 26-35.

Liker, Jeffrey $\mathrm{K}$. 1982

"Wage and Status Effects of Employment on Affective Well-Being Among Ex-Felons." American Sociological Review 47 Pp. 265-283.

Linden, Eric and James C. Hackler

1973

"Affective Ties and Delinquency". Pacific Sociological Review 16 Pp.27-46.

Lipton, Douglas, Robert Martinson and Judith Wilks 1975

The Effectiveness of Correctional Treatment.

New York: Praeger.

Little, Craig B. 1979

"Delinquent Behavior and Trouble with the Police in a Non-Metropolitan Area." Unpublished paper.

Logan, Charles H. 1972

"Evaluation Research in Crime and Delinquency: A Reappraisal." Journal of Criminal Law, Criminology and Police Science 63:378-387.

Maccormick, Austin $\mathrm{H}$.

1931 The Education of Adult Prisoners. New York: The National Society of Penal Information.

Mangrum, Claude $\mathrm{T}$. 1976

"Corrections' Tamishod Halo." Federal Probation $40: 9-14$.

Mann, W. E. 1967

Society Behind Bars: A Sociological Scrutiny of Guelph Reformatory. Toronto, Social Service Publishers.

Marsh, John J. 1973

"Higher Education in American Prisons." Crime and Delinquency Literature (March) :139-141. 
Martinson, Robert

1974 "What Works? - Questions and Answers About Prison

Reform" The Public Interest Pp.22-54.

Martinson, R., T. Palmer and S. Adams

1976 Rehabilitation, Recidivism and Research. Hackensack, N.J.: National Council on Crime and Delinquency.

Mocleery, Richard 1960

"Communication Patterns as Bases of Systems of Authority and Power." Pp. 49-77 in R. A. Cloward, L, E. Ohlin, G. M. Sykes and S. L. Messenger Theoretical Studies in Social Organization of the Prison. New York: Social Science Research Council, (March) Pamphlet 15, Pp. 49-77.

MoCollum, Sylvia G.

1971 "Say, Have You Got Anything Around Here for A Dumy?" Federal Probation 35 (September) :37-42.

MoCollum, Sylvia G.

1977 "What Works? A Iook at Effective Correctional Education and Training Experiences." Federal Probation 4I (June) : $32-35$.

McDougall, Ellis C.

1976 "Corrections Has Not Been Tried." Criminal Justice Review (Spring):63-76.

McLaren, David

1973

"Cons, Hacks and Educated Screws - The Prison Politics of Discipline and Rehabilitation." Canadian Journal of Criminology and Corrections 15:25-38.

Moberg, David O. and Richard C. Ericson 1972

"A New Recidivism Outoome Index." Federal Probation 36 (June) :50-57.

Nunnally, Jum C. 1967

Psychometric Theory New York: MoGraw-Hill Book Company.

Ohlin, Lloyd

1954

\footnotetext{
"The Stability and Validity of Parole Experience Tables" Unpublished Doctoral Dissertation, University of Chicago (Processed) Cited in Eva Iee Homer "Inmate-Family Ties: Desirable but Difficult." Federal Probation 43, no. 1, 1979 Pp. 47-86.
} 
Ontario Institute for Studies in Education

1979

Report to the Solicitor General of Canada conceming The Educational Program of the Canadian Corrections System. Ottawa: Canadian Penitentiary Service.

Palmer, Ted 1976

"Martinson Revisited." Pp. 4l-62 in R. Martinson, T. Palmer and S. Adams Rehabilitation, Recidivism and Research. Hackensack, N.J.: National Council on Crime and Delinquency.

Parlett, T. A. A. and J. D. Ayers

"The Modification of Criminal Personality Through Massed Leaming by Programmed Instructor." Canadian Journal of Criminology and Corrections 13 (2), 1971 Pp. 155-165.

Parlett, T. A. A. 1974

The Development of Attitudes and Morality in Adult Offenders. Unpublished Ph.D. Dissertation, University of Victoria.

Parlett, T. A. A., J. D. Ayers and D. M. Sullivan 1975

"Development of Morality in Prisoners.". Pp. 76-85 in The Teaching of Values in Canadian Education. Yearbook of the Canadian Society for the Study of Education (June).

Parlett, T. A. A. 1980

"Education - A Necessary if Not Sufficient Modality in The Correction of Penitentiary Inmates." Paper presented at the Annual Meeting of the Academy of Criminal Justice Sciences, OkIahoma City, March 13.

Pocket Criminal code 1980 Agincourt, Ontario: The Carswell Company Itd.

Quay, Herbert C. 1977

"The Three Faces of Evaluation: What Can Be Expected to Work." Criminal Justice and Behavior (December): $341-354$.

Reagen, Michael V. and Donald M. Stoughton 1976 School Behind Bars: A Descriptive Overview of Correctional Education in the American Prison System. Metuchen, N.J.: The Scarecrow Press. 
Reagen, Michael V. and Donald M. Stoughton

1976 "A Study of Prisoner Education Today." Pp. 49-96 in

Michael V. Reagen and Donald M. Stoughton (eds.)

School Behind Bars. Metuchen, N.J.: The Scarecrow

Press.

Reker, Gary T. and John A. Meissner

1977 "Iife Skills in a Canadian Federal Penitentiary: An

Experimental Evaluation." Canadian Joumal of

Criminology and Corrections 19 (July):292-302.

Roberts, Albert L.

1971

Sourcebook on Prison Education: Past, Present and Future. Springfield, Ill.: Charles C. Thomas.

Roberts, Albert R. (ed.)

1973 Readings in Prison Education. Springfield, III.

Robinson, James and Gerald Smith

1971 "The Effectiveness of Correctional Programs."

Crime and Delinguency (January) :67-80.

Roesch, Ronald and Raymond R. Corrado

1979 "The Policy Implications of Evaluation Research: Some Issues Raised by the Fishman Study of Rehabilitation and Diversion Services." The Journal of Criminal Law and Criminiology 80:530-541.

Saden, S. J.

1962 "The Educational Treatment Program for Corrections at Jackson, Mich." Journal of Correctional Education $15: 22-26$.

Schnur, Alfred C. 1948

"The Educational Treatment of Prisoners and Recidivism" American Joumal of Sociology 54:142-147.

Seashore, Marjorie, Steven Haberfeld, John Irwin and Keith Baker

1976 Prisoner Education: Project Newgate and Other College Programs. New York: Praeger.

Sechrest, Iee, Susan O. White and Elizabeth D. Brown

1979 The Rehabiliation of Criminal Offenders: Problems and Prospects. Washington, D.C.: National Academy of Sciences.

Serrill, Michael S. 1975

"Is Rehabilitation Dead?" Corrections Magazine

(May/June) Pp. 3-12, 21-26. 
Smith, Alexander B. and Louis Berlin 1977

"Can Criminals Be Treated?" New England Joumal on Prison Law (Spring):487-502.

Spencer, C. and J. Berecochea 1971

"Vocational Training at the California Institute for Women: An Evaluation." (Processed) Cited in David Greenberg Corrections and Punishment. Beverly Hills: Sage.

Stark, Werner

The Social Bond: An Investigation into the Bases of Law-abidingness. Volume One.

Stratton, John R. 1967

"Differential Identification and Attitudes Toward the Law." Social Forces 45:256-262.

Street, D.

1963 "Inmate Social Organization in Custodial and Treatment Settings." (Processed) Cited in Morgan V. Lewis et al. Prison Education and Rehabilitation: Illusion or Reality? Pennsylvania: Institute for Research on Human Resources, 1973.

Sullivan, Clyde and Wallace Mandell

1967 "Restoration of Youth Through Training: A Final Report." Staten Island, N.Y.: Wakoff Research Center (Processed). Cited in Douglas Iipton, Robert Martinson, and Judith Wilks The Effectiveness of Correctional Treatment. New York: Praeger, 1975.

Sutherland, Edwin H. and Donald R. Cressey 1978 Criminology. Tenth Edition. Philadelphia: J. B. Lippincott.

Sykes, Gresham M. 1958

The Society of Captives. Princeton: Princeton University Press.

Sykes, G. M. and Sheldon L. Messinger

1960 "The Inmate Social System" in Richard Cloward et al., Theoretical Studies in the Social Organization of the Prison. New York: Social Science Research Council.

Thomas, Charles W. 1975

"Theoretical Perspectives on Alienation in the Prison Society: An Emperical Test". Pacific Sociological Review 18:483-499. 
Thomas, Charles W. 1977

"Prisonization and its Consequences: An Examination of Socialization in a Coercive Setting." Sociological Focus 10, no. 1:53-68.

Thomas, Charles W. and Samuel C. Foster

1972

"Prisonization in the Inmate Contraculture." Social Problems 20:229-239.

Thomas, Charles W. and Samuel C. Foster 1973

"The Importation Model Perspective on Inmate Social Roles: An Emperical Test." The Sociological Quarterly 14:226-234.

Tittle, $\mathrm{C}$. 1964

"Social Organization of Prisoners." Social Forces $43: 216-221$.

Toch, Hans 1981

"A Revisionist View of Prison Reform." Federal Probation Vol. 45 no. 2 Pp. 3-9. June.

Weir, J. Donald 1973

"A History of Education in Canadian Federal Corrections." Pp. $39-47$ in Albert R. Roberts (ed.) Readings in Prison Education. Springfield: Charles C. Thomas.

Wellford, Charles 1967

"Factors associated with Adoption of the Inmate Code: A Study of Normative Socialization." The Joumal of Criminal Law, Criminology and Police science 58:197-203.

Wheeler, Stanton 1961

"Socialization in Correctional Commities." American Sociological Review 26, Pp. 699-712.

Wilkins, I. T. and P. MaNaughton-Smith 1964

"New Prediction and Classification Methods in Criminology." Joumal of Research in Crime and Delinquency $1: 19-21$.

Wilks, Judith and Robert Martinson 1976

"Is the Treatment of Criminal Offenders Really Necessary?" Federal Probation 40 (March) :3-9.

Wilson, James Q. 1975

Thinking About Crime. New York: Basic Books 
Wilson, James Q. 1980

" 'What Works?' Revisited: New Findings on Criminal Rehabilitation". The Public Interest 61:3-17.

Wright, Kevin N. 1980

"A Re-Examination of Correctional Alternatives." International Joumal of Offender Therapy and Comparative Criminology. V.24, no. 2, Pp. 179-192.

Yahraes, Herbert 1973

"The Re-education of Criminals." Pp. 180-195 in Albert R. Roberts (ed.) Readings in Prison Education. Springfield: Charles C. Thomas.

Zink, Theodore $M$. 1970

"A Study of the Effect of Prison Education on Societal Adjustment." "Journal of Corrective Education 22, no. 2, Pp. 18-20.

Zivan, Morton 1966

"Youth in Trouble: A Vocational Approach." Dobbs Ferry, N.Y.: Children's Village (Processed). Cited in Douglas Lipton, Robert Martinson and Judith Wilks The Effectiveness of Correctional Treatment. New York: Praeger, 1975. 